REVIEW ARTICLE

\title{
Recent Results and Future Challenges in the Assessment of Fetal Brain Function
}

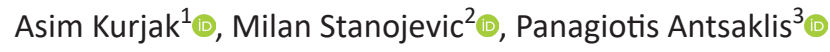

\begin{abstract}
Clinical and epidemiological studies have revealed that cerebral palsy (CP) most often results from prenatal rather than perinatal or postnatal causes. Currently, although the momentous advances in prenatal and perinatal care, there is no mean to identify or expect the development of these disorders. Therefore, the development of diagnostic strategies to avoid and condense the saddle of perinatal brain damage has to turn into one of the most imperative tasks of contemporary perinatal medicine. The application of the new neurobehavioral test KANET might improve our understanding of prenatal neurodevelopmental events and possibly antenatal detection of CP and other neurological diseases. Keywords: Cerebral palsy, KANET test, Prenatal neurology, Structure and function of fetal brain.

Donald School Journal of Ultrasound in Obstetrics and Gynecology (2021): 10.5005/jp-journals-10009-1682
\end{abstract}

\section{INTRODUCTION}

Understanding the structure and function of the fetal nervous system has been the dream of physicians for centuries. The pioneering efforts of lan Donald in obstetric ultrasound in the latter part of the 20th century have permitted this dream to become a reality. The initial contribution of obstetric ultrasound focused on normal and abnormal structures. Initially, anencephaly was described and followed by increasingly subtle central nervous system (CNS) abnormalities such as agenesis of the corpus callosum. The current and evolving challenge for investigators in obstetric ultrasound is to have similar success with the understanding of fetal neurological function. There are many functional neurological abnormalities such as cerebral palsy (CP) whose causes are poorly understood. There is also an escalating number of results illustrating that a large presence of neurological problems, such as minimal cerebral dysfunction, schizophrenia, epilepsy, or autism, upshot at least in part from prenatal neurodevelopmental problems. Clinical and epidemiological studies have revealed that CP most often results from prenatal rather than perinatal or postnatal causes. ${ }^{1}$ Currently, although the momentous advances in prenatal and perinatal care, there is no mean to identify or expect the development of these disorders. Therefore, the development of diagnostic strategies to avoid and condense the saddle of perinatal brain damage has to turn into one of the most imperative tasks of contemporary perinatal medicine. The application of the new neurobehavioral test KANET might improve our understanding of prenatal neurodevelopmental events and possibly antenatal detection of $\mathrm{CP}$ and other neurological diseases.

\section{Structural and Functional Development OF CNS}

\section{Structural Development of CNS}

The development of CNS begins approximately at the end of gastrulation. The generation of the neuroectoderm from ectoderm during the third postconceptional week results in the formation of the neural plate. Thus, the neural epithelium of the embryo, which is a precursor of neurons and glia, is virtually the first part of an organism that acquires a separate identity from other cells. ${ }^{2}$

\footnotetext{
${ }^{1}$ Sarajevo Medical School, Sarajevo School of Science and Technology, Sarajevo, Bosnia and Herzegovina

${ }^{2}$ Department of Obstetrics and Gynecology, Medical School University of Zagreb, Sveti Duh Hospital, Zagreb, Croatia

${ }^{3}$ Department of Obstetrics and Gynecology, University of Athens, Greece

Corresponding Author: Asim Kurjak, Sarajevo Medical School, Sarajevo School of Science and Technology, Sarajevo, Bosnia and Herzegovina, Phone: +385 91 4512096, e-mail: asim.kurjak@public.carnet.hr

How to cite this article: Kurjak A, Stanojevic M, Antsaklis P. Recent Results and Future Challenges in the Assessment of Fetal Brain Function. Donald School J Ultrasound Obstet Gynecol 2021;15(1): 10-37.

Source of support: Nil

Conflict of interest: None
}

The formation of the neural plate is succeeded by the folding of its edges and formation of a neural tube, whose further growth and reshaping results in the formation of structures of CNS. According to O'Rahilly and Muller, the forebrain (prosencephalon), midbrain (mesencephalon), and hindbrain (rhombencephalon) can be distinguished in the rostral portion of the unfused neural folds ${ }^{3}$ earlier than it is usually referred to, approximately at the $22 \mathrm{nd}$ postconceptional day. In the rapid succession, during the 4 th postconceptional week, the forebrain components-diencephalon and telencephalon can be detected. Three embryonic zones, ventricular, intermediary, and marginal zone (seen from ventricular to the pial surface), are present in all parts of the neural tube, while telencephalon contains additional two zones, subventricular and subplate zone, Ventricular zone and subventricular zone of telencephalon are the site of neurogenesis and all the future neurons and glia are born in these structures. During migration toward the pial surface, they form other transitional zones before reaching their genetically predetermined final destinations. Those destinations are cortical plate or different nuclei in the brain stem, diencephalon, and basal forebrain [for references, see ${ }^{1}$ ]. One of the transitional structures, a subplate zone that is a site for transient 
synapses and neuronal interactions, can play a major role in the developmental plasticity following perinatal brain damage. ${ }^{4}$ Early appearance of interneuronal connections, shown in Table 1, implicates a possibility of early functional development. However, these first synapses exist only temporarily and disappear due to the normal reorganization processes. Most embryonic zones, types of neurons and glia, and early synapses, which play a crucial role in certain periods of fetal brain development, eventually disappear, significantly changing the structure and function of the brain. Reorganization processes include apoptosis, the disappearance of redundant synapses, axonal retraction and transposition, and the transformation of the neurotransmitters phenotype. ${ }^{4}$

Table 1 shows a significant overlap of neurogenesis, migration, and synaptogenesis in embryonic and fetal life. The development of the human brain is not completed at the time of delivery. In an infant born at term, characteristic cellular layers can be observed in motor, somatosensory, visual, and auditory cortical areas. Although proliferation and migration are completed in a term infant, synaptogenesis and neuronal differentiation continue very intensively. ${ }^{5}$ Brain stem demonstrates a high level of maturity, whereas all histogenetic processes actively persist in the cerebellum. ${ }^{6}$ Therefore, only subcortical formations and the primary cortical areas are well developed in a newborn. The associative cortex, barely visible in a newborn, is scantily developed in a 6-month-old infant. Postnatal formation of synapses in associative cortical areas, which intensifies between the 8th month and 2nd year of life, precedes the onset of first cognitive functions, such as speech. Following the 2 nd year of age, many redundant synapses are eliminated. The elimination of synapses begins very rapidly and continues slowly until puberty when the same number of synapses as seen in adults is reached. ${ }^{6}$

\section{Functional Development of CNS and Role of Four- dimensional Ultrasound (4D US)}

The first synapses appear in the spinal cord at 6-7 postconceptional weeks ${ }^{7}$ and in the cortical plate at 8 postconceptional weeks. ${ }^{8}$ This is the phase when the first electrical bustle and conduction of information take place. The earliest spontaneous fetal movements can be observed at 7.5 postconceptional weeks. These movements, consisting of slow flexion and extension of the fetal trunk, accompanied by the inactive displacement of arms and legs and emerging in asymmetrical sequences, have been described as "vermicular". 9,10 They are substituted by various general movements (GMs), which consist of head, trunk, and limb movements, such

Table 1: Dynamics of the most important progressive processes in the development of the human brain

\begin{tabular}{llll}
\hline & Beginning & $\begin{array}{l}\text { Most intensive } \\
\text { activity }\end{array}$ & Ending \\
\hline Neurogenesis & $\begin{array}{l}\text { Early embryonic } \\
\text { period (4th } \\
\text { week) }\end{array}$ & 8th-12th week & $\begin{array}{l}\text { Approx. 20 } \\
\text { weeks }\end{array}$ \\
& $\begin{array}{l}\text { Simultane- } \\
\text { ously with } \\
\text { proliferation }\end{array}$ & $\begin{array}{l}\text { 18th-24th } \\
\text { week }\end{array}$ & 38th week \\
Synaptogenesis & $\begin{array}{l}\text { 6th-7th week- } \\
\text { spinal cord, 8th } \\
\text { week-cortical } \\
\text { plate }\end{array}$ & $\begin{array}{l}\text { 13th-18th } \\
\text { week, after } \\
\text { 24th week, 8th } \\
\text { month-2 year } \\
\text { of postnatal life }\end{array}$ & \\
\hline
\end{tabular}

as "rippling" seen at week 8, "twitching" and "strong twitching" at weeks 9 and 9.5, respectively, and "floating" "swimming" and "jumping" at week $10 .{ }^{11}$ Isolated limb movements emerge almost simultaneously with the GMs. At the same time with the beginning of spontaneous movements, at 7.5 postconceptional weeks, the initial motor reflex activity can be detected, permitting the hypothesis to be made of the existence of the first afferent-efferent circuits. ${ }^{7}$ At that time, head tilting following perioral stimulation was noted. The primary reflex movements are immense and signify a limited number of synapses in a reflex pathway. During the 8th week of gestation, these substantial reflex movements are replaced with local movements, possibly due to an increase in the number of axodendritic synapses. Hands become susceptible at 10.5 weeks and lower limbs start to contribute to these reflexes at around week 14. General movements are the first sign of a supraspinal control on fetal motor activity. Approximately at the 7 postconceptional weeks, the brainstem which consists of the medulla oblongata, pons, and midbrain, begins to develop and mature in a caudal to the rostral direction. As the medulla matures in advance of more rostral structures of the brainstem, reflexive movements of the head, body, and extremities, as well as breathing movements and heart rate alterations, appear in advance of other functions. ${ }^{12}$ From the 10th week onward, the amount and incidence of movements increase. By 14-19 weeks, fetuses are highly active with the longest period between movements of only 5-6 minutes. In the 15 th week, 15 singular types of movement can be observed. The general body movements and isolated limb movements, retroflexion, anteflexion, and rotation of the head can be seen. Also, face movements, such as mouthing, yawning, hiccups, sucking, and swallowing, can be included to an ample repertoire of fetal motor activity in this stage. ${ }^{13}$ But, during the first half of pregnancy, a dynamic pattern of neuronal production and migration, as well as the immature cerebral circuits are considered too immature for cerebral involvement in the motor behavior. ${ }^{4}$ Merely at the end of this period do a quantifiable number of synapses appear in the structures preceding the cerebral cortex, perhaps forming a substrate for the first cortical electric activity, noted at week $19 .{ }^{4}$ The spinothalamic tract is established at the 20th week and myelinized by 29 weeks of gestation and the thalamocortical connections penetrate the cortical plate at 24-26 weeks. Evoked potentials can be detected from the cortex at the 29th week, indicating that the functional connection between periphery and cortex operates from that time onward..$^{14}$ In the second half of pregnancy, the number of GMs gradually decreases, particularly during the last 10 weeks. ${ }^{15}$ Although this decrease was first explained as a result of the reduction in amniotic fluid volume, it is now believed to be a result of maturation processes in the brainstem. ${ }^{12}$ Simultaneously with the decline in the number of generalized movements, an increase in facial movements, as well as opening or closing of the jaw, swallowing, and chewing, can be observed. These activities can be seen mainly in the periods of absence of GMs, and this pattern is considered to be a manifestation of the normal neurological development of the fetus. ${ }^{15}$ However, alterations not only in the number of movements but also in their complexity, are revealed to be the result of cerebral maturation processes. It is important to point out that subunits of the brainstem remain the main regulators of all fetal behavioral patterns until delivery. ${ }^{12}$ Despite medical reports from 100 years ago and $>30$ years of systematic research initiated by Prechtl and colleagues, ${ }^{16-18}$ the study of prenatal behavior is still in its infancy. One of the most promising advances in the field of ultrasonography has been the 
new 4D US technology. Its advance has been completed in the last year giving visualizations in almost real-time. ${ }^{19-22}$ The availability of new diagnostic data has in an extraordinary way raised our knowledge about intrauterine life, substantially modifying some earlier interpretations. ${ }^{23}$ First spontaneous fetal movements can be observed with conventional two-dimensional ultrasound (2D US) around 8th gestational week, while the newly developed 4D US allows the visualization of fetal motility 1 week earlier (Table 2). ${ }^{24}$

General movements are the first complex fetal movement patterns observable by two-dimensional (2D) US, but assessment by the 4D US is a significant improvement. They can be recognized from the 8th to 9th weeks of pregnancy (Fig. 1 showed by 4D US) and continue to be present until 16-20 weeks after birth. ${ }^{18}$

According to Prechtl, these are gross movements, involving the whole body. They wax and wane in intensity, force, and speed, and they have a gradual beginning and end. ${ }^{13,18}$ The majority of sequences of extension and flexion of the legs and arms is complex and may be better assessed with 4D US. ${ }^{24}$ In the literature, there is a range between the 8th and 12th weeks concerning the first appearance of limb movements. ${ }^{13,18,20,25}$ Isolated arm and leg movements found by de Vries et al. at the 8 th week of gestation. ${ }^{13}$ With 4D US, limb movements at the 8th to 9th weeks were found. Using 4D sonography, Kurjak et al. found that from 13 gestational weeks onward, a "goal orientation" of hand movements appears and a target point can be recognized for each hand movement. ${ }^{19}$ More limb joints are active and move simultaneously, such as extension or flexion in arm and elbow or hip and knee. The elevation of the hand, extension of the elbow joint, with a slight change in direction and rotation, can be seen simultaneously. ${ }^{26}$ The isolated limb movements seen at the 9th week are followed by the appearance of the movements in the elbow joint at 10 weeks, changes in finger position in the 11th week and by easily recognizable clenching and unclenching of the fist at the 12th to 13 th weeks. Finally, at the 13th to 14 th weeks, isolated finger movements can be seen, as well as an increase in the activity and strength of the hand or finger movements. ${ }^{26}$ Recent investigation of fetuses in the last trimester of gestation, performed by 4D US, has discovered an even wider range of hand and face movements than was formerly explained..$^{19}$ It has been also confirmed that the fetal movement patterns in the second half of pregnancy are about

Table 2: Developmental sequence of fetal behavioral patterns observed by 4D US in the first trimester of pregnancy (ref.)

\begin{tabular}{|c|c|c|c|c|c|}
\hline \multirow[b]{2}{*}{ Type of movements } & \multicolumn{5}{|c|}{ Postconceptional weeks } \\
\hline & 7 & 8 & 9 & 10 & 11 \\
\hline General movement & + & + & + & + & + \\
\hline Startle & & + & + & + & + \\
\hline Stretching & & + & + & + & + \\
\hline Isolated arm movement & & + & + & + & + \\
\hline Isolated leg movement & & + & + & + & + \\
\hline Head rotation & & & + & + & + \\
\hline Head anteflexion & & & + & + & + \\
\hline Head retroflexion & & & + & + & + \\
\hline
\end{tabular}
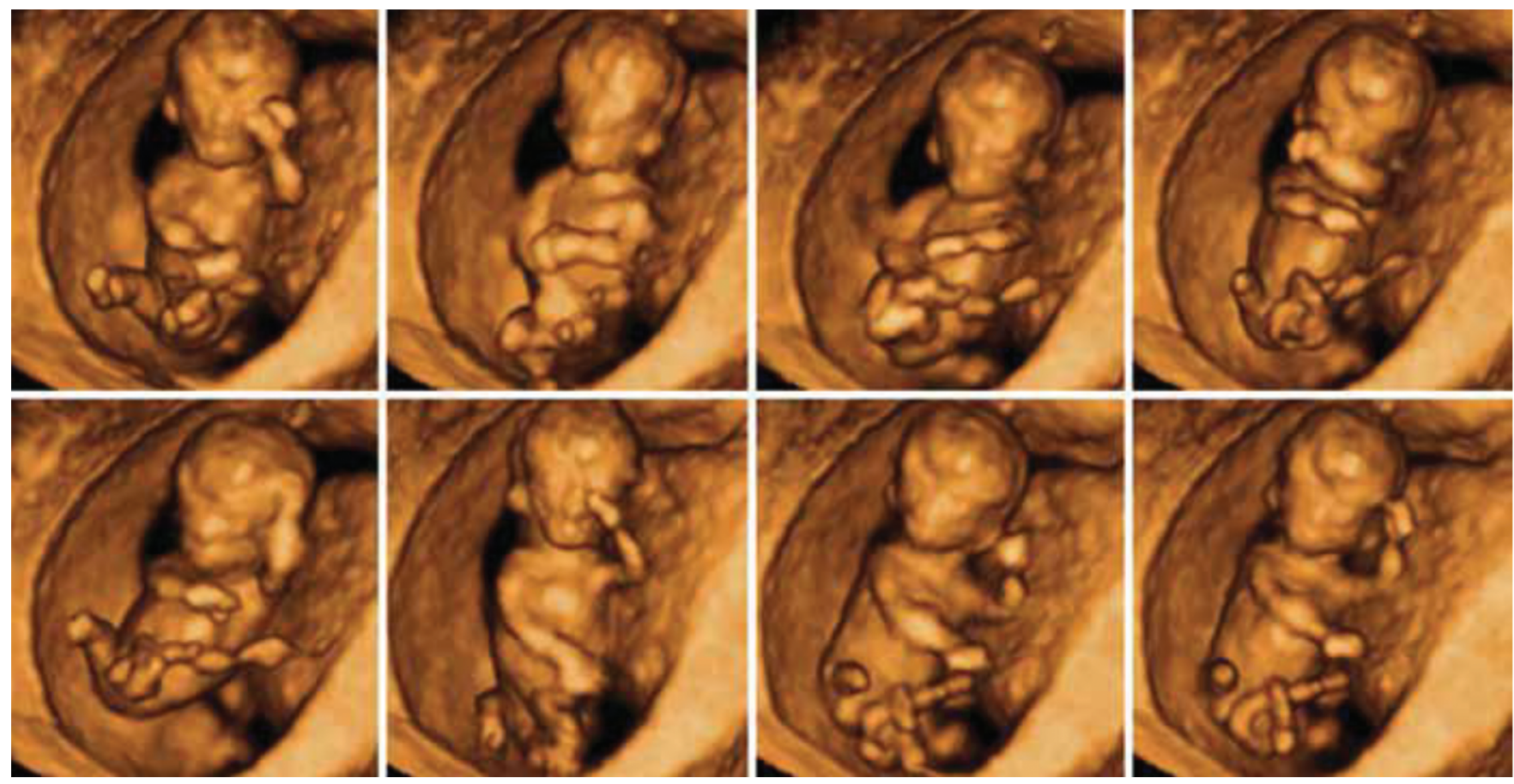

Fig. 1: 4D US imaging demonstrated fetus at 13 weeks of gestation showing general movement pattern 
equal to those monitored after birth, while the list of movements in the newborn consists of some patterns that cannot be watched in the fetus, such as the Moro reflex. ${ }^{27}$ As well, study of anencephalic fetuses has presented clear evidence for the influence of supraspinal structures on motor behavior at around the 20th gestational week. In these fetuses, the number of movements was normal or even increased, but the complexity of the movement patterns distorted radically and movements were stereotyped and simplified. ${ }^{28}$

The eminence of fetal movement patterns is distorted in fetuses undergoing intrauterine growth restriction. The activities become slower and monotonous, similar to cramps and their variability in force and amplitude is reduced. ${ }^{29}$ These changes might designate the subsistence of brain lesions in growth-restricted and possibly hypoxic fetuses. Despite the premature postulations, the changes in the amplitude and complexity of movements in these fetuses do not show to be due to oligohydramnios. In cases of premature rupture of fetal membranes and a subsequently reduced volume of amniotic fluid, movements arise less frequently, but their complexity look likes that of movements achieved in the normal volume of amniotic fluid. ${ }^{16}$ Qualitative including quantitative analysis of fetal movements divulged the consistency of the fetal nervous system, and can be applied for the recognition of different cerebral dysfunctions, and probably neuromuscular ailments.
The application of the new technology, 4D US, in the examination of fetal facial movements has revealed the existence of a full range of facial expressions including grimacing, tongue expulsion, and eye-lid movements (Fig. 2) similar to emotional expressions in adults. ${ }^{27,30}$ The possibility of studying such subtle movements might open a new area of investigation. ${ }^{31}$

During the first trimester, a tendency toward increased frequency of fetal GMs with increasing gestational age has been noticed (Fig. 3A). While at the beginning of the second trimester, the fetuses began to display a tendency toward increased frequency of observed fetal facial expression up to the end of the second trimester. An oscillation and dispersion of the incidence of the facial expression as seen in the polynomial regression of isolated eye blinking diagram is observable in Figure $3 \mathrm{~B}^{30}$

The most frequent facial movement patterns in the second trimester were isolated eye blinking, grimacing, suckling, and swallowing while yawning, mouthing, tongue expulsion, and smiling could be observed less frequently. ${ }^{25,30}$ During the third trimester, the fetuses began to display decreasing or stagnant incidence of fetal facial expression. All of the types of head movements and hand-to-body contact indicated a tendency to decrease frequency from the beginning of the second trimester to the end of the third trimester (Fig. 3C). ${ }^{30}$
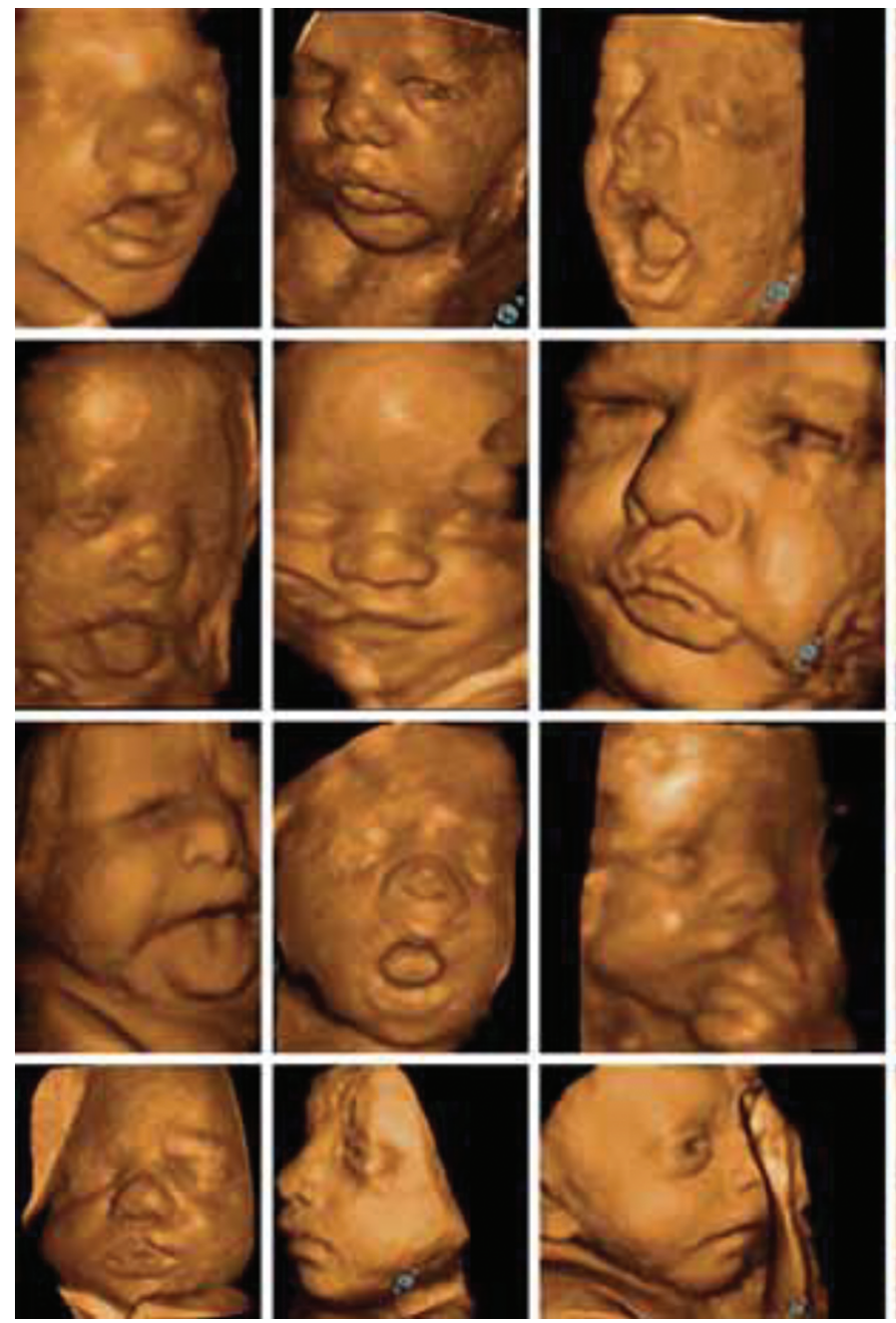
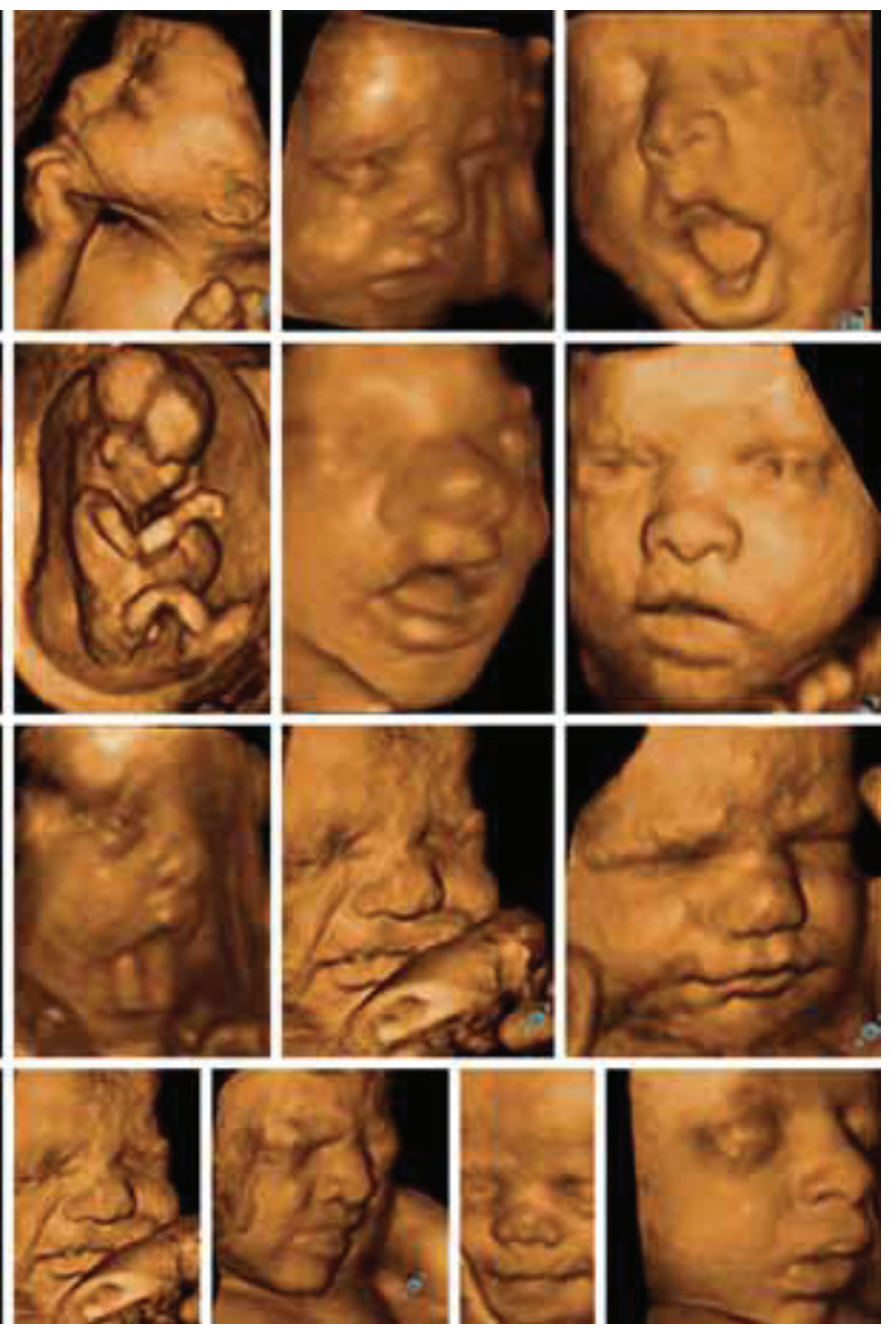

Fig. 2: 3D/4D US provides a clear depiction of dynamic changes of fetal facial expression allowing the study of fetal behavior during all trimesters of pregnancy 
The investigations of fetal facial expressions established that all mechanisms of the fetal yawning pattern, prolonged jaw opening followed by a quick closure and accompanied by head flexion and elevation of arms, can easily be documented by 4D US in this period (Fig. 4). ${ }^{32}$

If the fetal yawning in the third trimester was matched up to the yawning in the neonates during the first week of life, no differences were found in the frequencies of this reaction. The frequency of yawning steadily increased between the 15th and 24th week when a short plateau was observed from 24th to 26th week and was followed by a slight decrease toward the term. ${ }^{30}$ A gestational age-related tendency in the frequency of yawning could be assumed as the maturation of the brain stem and probably the gaining of control of more cranial structures over yawning pattern. These results have offered new data concerning the route of neurodevelopment of this fascinating, but poorly implicit reflex. Whether this is distorted in cases of neurodevelopmental disorders and whether such adaptations can give us impending into the function of fetal nervous system in high-risk pregnancies, continues to be determined. It also stays to be determined to what possibility are the facial motoric patterns related to the function and integrity of the CNS. However, the fact that even in the embryonic stage, the identical inductive forces that cause growth and restyling of the neural tube influence the development of facial structures, and that many genetic disorders affecting the CNS are also described by dysmorphology and dysfunction of facial structures, underline the value of these studies. ${ }^{2,30,31}$

\section{Neonatal Aspect of Fetal Neurology}

Obstetric aspects of fetal neurology have been discussed extensively in our previous publications. ${ }^{19-25,27-31}$ To better understand fetal neurobehavioral patterns, we have learned a lot from basic studies of brain development and clinical postnatal studies of neonates. Now, when we have reached the edge of a fetal behavioral investigation by 4D US in normal fetuses, we intend to find some new ideas and ways of investigation presenting a neonatal aspect of fetal neurology.

Cerebral palsy is an "umbrella" term for disorders of development, movement, and posture, resulting in limitations of activity due to nonprogressive impairment of the developing brain. ${ }^{33}$ The diagnosis of CP is retrospective and it is exceptionally made before the age of 6 months in only the most severely affected infants, and the specificity of the diagnosis will improve as the child ages and the nature of the disability evolves. ${ }^{34}$ Cerebral palsy does not result from a single event but rather there is a sequence of interdependent adverse events providing to the condition. ${ }^{35}$ This time frame of evolving adverse events is something that should be taken into account when considering the possibility of $\mathrm{CP}$ diagnosis in infants. ${ }^{34,35}$ The understanding of the profile of a child's disability across multiple domains is an ongoing process necessary for appropriate treatment and future planning. ${ }^{34}$ This theoretical statement is sometimes very difficult to be practically implemented. An attempt to make an early diagnosis of CP should be followed with factors related to pathogenesis, impairment, and functional limitations in every patient. ${ }^{34}$ To identify the pathogenesis of the process, neuroimaging methods should be used, among which cranial ultrasound, magnetic resonance imaging (MRI), magnetic resonance spectroscopy, and diffusion-weighted imaging are the most frequently used in very low birth-weight premature infants and term infants with encephalopathy. ${ }^{34}$ Impairment of organs or systems by clinical assessment of muscle tone, strength, and control
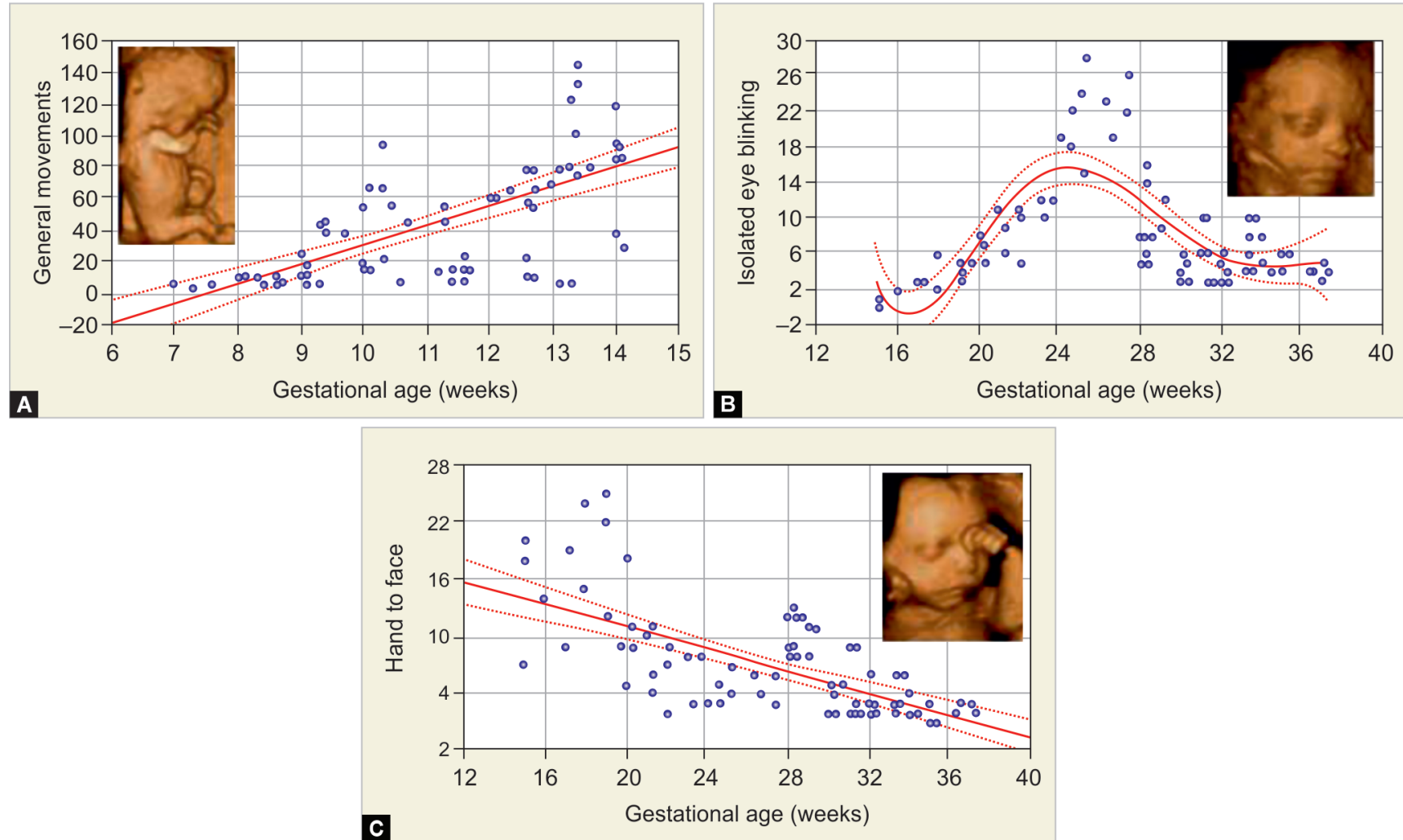

Figs 3 A to C: Quantitative analysis of normal fetal behavior patterns using 4D-US (A) General movements; (B) Hand to face movement; (C) Isolated eye blinking ${ }^{30}$ 

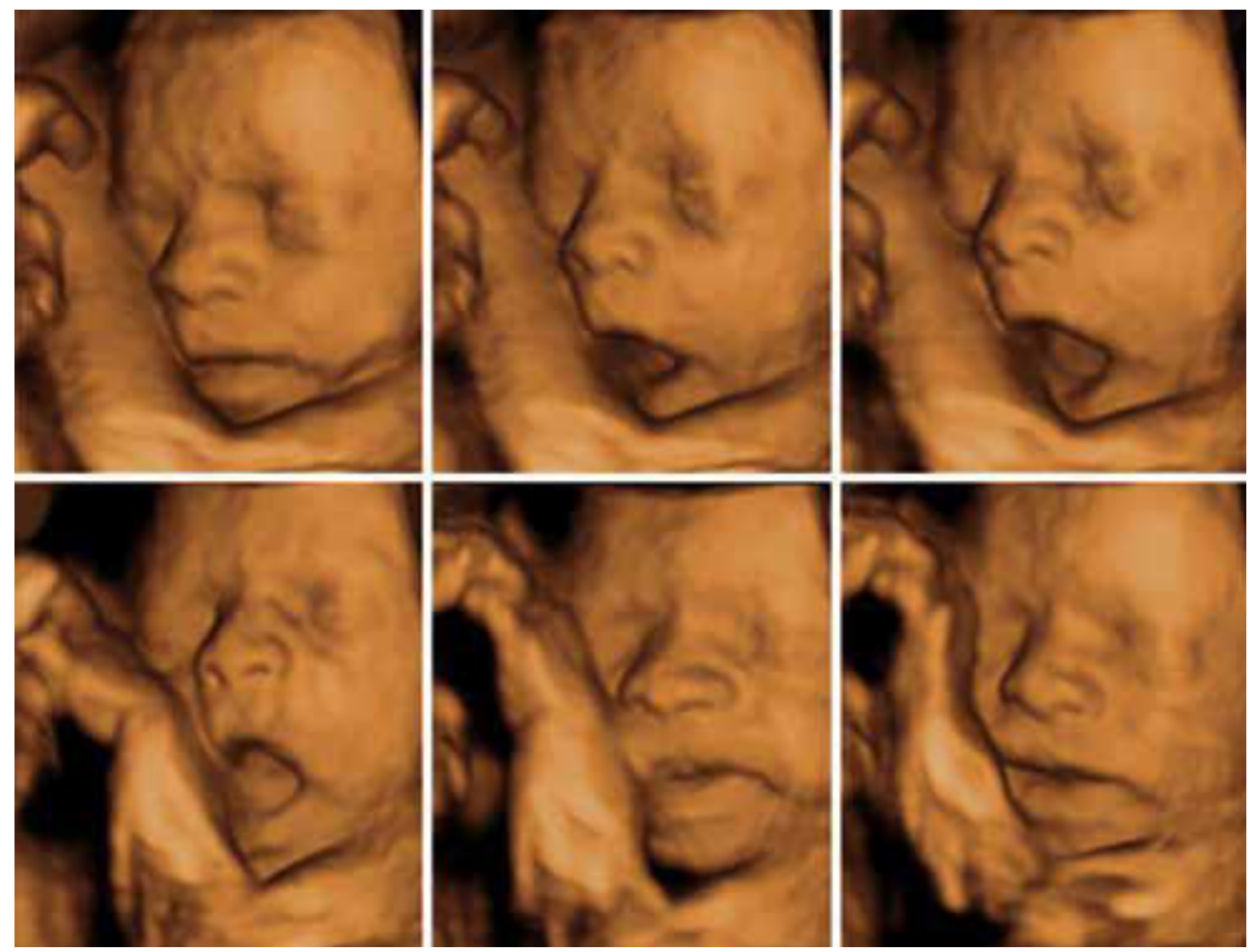

Fig. 4: 4D US image sequences of facial expression characterized by stereotyped yawning opening

of voluntary movements for early detection of infants with the risk for CP has been frustrating because only $43 \%$ of 7-year-old children with CP had a normal newborn neurological examination. ${ }^{34,36}$ Is it possible to change this discouraging fact resulting from our failure to diagnose neurological impairment early enough to intervene? Interests in the diagnosis of neurological impairment among ultrasonographers using 4D US have been recently shifted toward the prenatal period. ${ }^{23,37}$ Is there any possibility to improve the timing of the postnatal diagnosis of a neurologically disabled infant? Postnatal assessment is probably easier to perform than prenatal, by using a simple and suitable for everyday work screening clinical test with good reliability, specificity, and sensitivity. Such tests are still not widely used, while those complicated and timeconsuming are used mostly for clinical research purposes. There is a possibility for the early and simple neurological assessment of the term and preterm newborns to detect associated risks and anticipate the long-term outcome of the infant, and to establish a possible causative link between pregnancy course and neurodevelopmental outcome. ${ }^{38} \mathrm{As} C \mathrm{CP}$ is a disorder of movement and postural control resulting in functional limitations, its diagnosis could be helpful in the detection of early impairment. ${ }^{34}$ Clinical neurological assessment proposed and practiced by Amiel-Tison could be very useful in the early detection of newborns at risk. ${ }^{38}$ As the development of the CNS is a very complex and longlasting process, the assessment of its developmental optimality is something that should be assessed to investigate whether the infant is neurologically normal or damaged. Neurological assessment at term by Amiel-Tison is taking into account neurological maturation exploring so-called lower subcortical system developing earlier from the reticular formation, vestibular nuclei and tectum, and upper cortical system developing from the corticospinal pathways. ${ }^{39}$ The role of the lower system is to maintain posture against gravity, while the upper system is responsible for the control of erect posture and the movements of the extremities. ${ }^{39}$ At the corrected age of 40 gestational weeks optimality assessment consists of head circumference measurement, assessment of cranial sutures, visual pursuit, social interaction, sucking reflex, raise-to-sit and reverse, the passive tone in the axis, the passive tone in the limbs, fingers, and thumbs outside the fist, and autonomic control during the assessment. ${ }^{39}$ The Amiel-Tisson neurologic assessment at term is increasing accuracy in assessing CNS function in the neonate by using a simple scoring system, focusing on the most meaningful items, promoting a clinical synthesis at term, for the term and preterm infants. ${ }^{39}$ It was recognized that clinico-anatomic correlations using high-resolution neuroimaging techniques could be helpful in the neurological assessment of newborns, while the neurological examination and the functional assessment of the developing CNS are bringing a new perspective of CNS status in the neonatal period. ${ }^{40}$

\section{Postnatal Assessment of GMs}

In the last 30 years, objective assessment of videotaped GMs by Prechtl's method is predictive of later CP.9,16,18,41 The quality of GMs at 2-4 months post-term (so-called fidgety GM age) has been found to have the highest predictive value in the detection of infants at risk for CP development. ${ }^{42}$ It seems that assessment of the quality of GM is a window for early detection of children at high risk for developmental disorders. ${ }^{17,42}$ The method is simple and it is based on the so-called Gestalt evaluation of GM complexity and variation. ${ }^{17,41,42}$ Assessment of GMs at 2-4 months post-term at so-called fidgety GM age has been found to have the highest predictive value for the development of CP if abnormal. ${ }^{17,41,42}$

Heinz Prechtl's work enabled that spontaneous motility during human development has been brought into the focus of 
interest of many perinatologists prenatally and developmental neurologists postnatally. ${ }^{9,16,18,41,42}$ According to the research preceding Prechtl's ingenious idea, during the development of the individual the functional repertoire of the developing neural structure must meet the requirements of the organism and its environment. ${ }^{41}$ This concept of ontogenetic adaptation fits excellently to the development of the human organism, which is during each developmental stage adapted to the internal and external requirements. ${ }^{41}$ Prechtl stated that spontaneous motility, as the expression of spontaneous neural activity, is a marker of brain proper or disturbed function. ${ }^{41,42}$ The observation of an un-stimulated fetus or infant which is the result of spontaneous behavior without sensory stimulation is the best method to assess its CNS capacity. ${ }^{41}$ All endogenously generated movement patterns from the un-stimulated CNS could be observed as early as from the 7-8 weeks of postmenstrual age, with developing a reach repertoire of movements within the next 2 or 3 weeks, continuing to be present for 5-6 months postnatally. ${ }^{13}$ This remarkable fact of the continuity of endogenously generated activity from prenatal to postnatal life is a great opportunity to find out those high-risk fetuses and infants in whom the development of neurological impairment is emerging. The most important among those movements are GMs involving the whole body in a variable sequence of arm, leg, neck, and trunk movements, with gradual beginning and the end. They wax and wane in intensity, force, and speed being fluent and elegant with the impression of complexity and variability. General movements are called fetal or preterm from 28 to 38 weeks of postmenstrual age, while after that we have at least two types of movements: writhing present to 46 to 52 weeks of postmenstrual age and fidgety movements present till 54 to 58 weeks of postmenstrual age. ${ }^{18,41,42}$ Lack of fluency and the existence of considerable variation and complexity are the main characteristics of mildly abnormal GMs. ${ }^{43}$ When complexity, variation, and fluency are absent then we are dealing with definitely abnormal GMs. ${ }^{43}$

The quality of each individual movement includes speed, amplitude, and force combined in one complex perception. ${ }^{13,18,41-44}$ Investigation of normal and neurologically impaired preterm infants showed that except for the higher incidence of clonus in the abnormal group, there was no marked difference in the number of different motor patterns studied. ${ }^{44,45}$ However, video analysis of another group of sick preterm infants revealed a "reduction of elegance and fluency as well as variability, fluctuation in intensity and speed rather than any change in the incidence of distinct motor patterns". ${ }^{44-46}$ Based on postnatal studies, it would be very important to seek for abnormal quantity and quality of prenatal movements to find fetuses neurologically at risk. ${ }^{46}$

Some facts are very important in the assessment of GMs. The first is that the evaluation of GMs should be based on the video recorded movements either pre- or postnatally. The second fact is that when assessing GMs one should use so-called "gestalt perception", which could be described as the overall impression of GMs with a standardized procedure. ${ }^{41}$ During the perception, one should recognize the movement patterns of GMs, then assess their complexity, variability, and fluency. ${ }^{41,42}$ According to Hadders-Algra, GMs could be classified as normal-optimal, normal-suboptimal, mildly abnormal, and definitely abnormal. ${ }^{42}$ This modality of GM assessment is important for the prenatal and postnatal observation of GMs. It is not so important to assess the quantity of GMs, while the assessment of their quality is of utmost importance in terms of the prognosis of the neurodevelopmental outcome. They can better predict neurodevelopmental outcomes than classical neurologic examination alone. ${ }^{47}$

We can conclude that prenatal and postnatal assessment of GMs according to Prechtl's method gives quite new insight into the function and development of CNS. This important modality is time-consuming and requires some technology and expertise to be practiced, but the advantages of its implementation in prenatal and postnatal life are very promising and encouraging in terms of its prognostic value. Prenatal assessment of GMs is well developed and established, while prenatal assessment needs sophisticated real-time $4 \mathrm{D}$ ultrasonographic or other technology to enable a more precise assessment of GM quality in fetuses.

\section{Continuity of GMs from Prenatal to Postnatal Life}

Postnatal studies of neonatal behavior have taught us that the assessment of behavior is a better predictor of neurodevelopment disability than neurological examinations. ${ }^{46}$ It is important to mention that postnatal observation of movement patterns was introduced by Prechtl and coworkers in the way that they have been observing spontaneous movements of the infant using video typing and "off-line" analysis of both quantity and quality of the movement. ${ }^{17,48}$ They proved that assessment of GMs in highrisk newborns has significantly higher predictive value for later neurological development than neurological examination. ${ }^{46,47,49}$ Kurjak and coworkers conducted a study by 4D US and confirmed earlier findings made by the 2D US, that there is behavioral pattern continuity from prenatal to postnatal life. ${ }^{27}$ Assessment of neonatal behavior is a better method for early detection of $\mathrm{CP}$ than neurological examination alone..$^{50} \mathrm{It}$ is being speculated that intrauterine detection of encephalopathy would improve the outcome. Although many fetal behavioral studies have been conducted, it is still questionable whether the assessment of continuity from fetal to neonatal behavior could improve our ability of early detection of brain pathology. Early detection could possibly rise an opportunity to intervene and even prevent the expected damage.

\section{Could Some Postnatal Signs of Neurological Disability be Used Prenatally?}

It has been proven by now that ultrasonography is a powerful tool in the assessment of fetal behavior. Four-dimensional ultrasound brought up to light visual observation of the fetus, particularly in two especially important domains: fetal finger movements and facial expressions. ${ }^{19,51}$ This new technology is not only a toll of fetal observation but a very useful toll to evaluate the development of fetal CNS in normally developing fetuses and those at high risk. A basic understanding of fetal neurology include: defining of motor pathways involved, the chronology of their maturation, and the direction of myelination. ${ }^{52,53}$ This information helps the clinician in better interpretation of fetal movements. The experience acquired with Amiel-Tison's Neurological Assessment at Term (ATNAT) helps us in the interpretation of fetal movements. ${ }^{39,54,55}$

The domain of fetal neurology is already too extensive, but the focus of interest is mainly the second trimester, even though spontaneous fetal mobility emerges and has already became differentiated at a very early age. ${ }^{56}$ This means that we will take into consideration the period of pregnancy from 20 till 40 weeks of gestation, including the end of the neuronal migration and the post-migratory phase corresponding to the development of the neocortex. ${ }^{4,57}$ 
As it was already mentioned, $\mathrm{CP}$ describes a group of disorders of the development of movement and posture, causing activity limitations, which are attributed to nonprogressive disturbances occurring at the time of fetal brain development. ${ }^{58-61}$ Motor disorders that occur in patients with $\mathrm{CP}$ are often accompanied by disturbances of sensation, cognition, communication, perception, behavior, and/or seizure disorder. ${ }^{58-61}$ "Disturbances" is a term that refers to events or processes that in some way influence the expected pattern of brain maturation. ${ }^{55}$ Those events or processes are many, with consequences varying from very conspicuous to very subtle. It should be kept in mind what many neurologists emphasize, that morphology does not always correspond to the neurological outcome. ${ }^{39,54,55}$ The opposite view is the one from pediatricians and neurophysiologists, who are involved in longterm follow-up studies, and they are certainly not that optimistic. It would be wise to consider the long-run prognosis, for each specific type of fetal brain damage and make appropriate decisions for conservative management.

Hopes have been headed toward magnetic resonance (MR), but in many cases brain changes cannot be detected as early as the first year of life, like pathological gliosis which causes secondary hypomyelinization.

While examining the fetal head by $4 \mathrm{D}$, the sonographer should examine bony structures and fetal cranial sutures, if they are folding over one another, it is considered to be a bed sign previously described by Amiel-Tison. ${ }^{39,55}$ The same sign should be searched for postnatally, as a part of the neurological examination. ${ }^{62}$

The majority of pediatricians believe that the main obstacle for early prediction of CP based on a functional observation of the fetus such as visual observation by the 4D US is due to the "precompetent" stage of most of the motor behavior observed in utero. ${ }^{39,55}$ One of the possible signs detected could be a high arched palate, described by Amiel-Tison, in the clinical assessment of the infant nervous system. ${ }^{39,55}$ What was believed as undetectable became visible by 4D. Recently, the 3D "reverse face technique" has been described. This technique overcomes shadowing the fetal face by rotating the frontal facial image through $180^{\circ}$ along the vertical axis, so that the palate, nasal cavity, and orbits become visualized. ${ }^{63,64}$

In their early work, Pooh and Ogura examined 65 normal fetuses by $3 \mathrm{D} / 4 \mathrm{D}$. The purpose of their study was to investigate the natural course of fetal hand and finger positioning. ${ }^{26}$ During the 9 th and at the beginning of the 10th week fetal hands were located in front of the chest and no movements of wrists and fingers were visualized. From the middle of the 10th week, active arm movements were observed. ${ }^{26}$ This study is very important because it is showing that finger and thumbs movements begun in the early stage of human life, long before the maturation of the upper system. Therefore, this motor activity depends on the lower system and not before 30 and 32 weeks switches to the upper control.

Amiel-Tison also described the so-called neurologic thumb squeezed in a fist. Clenched fingers can also be detected by the 4D US, as well as overlapping cerebral sutures. ${ }^{19,26}$

Head anteflexion becomes visible during the 10th and 11th gestational week, according to de Vries et al. ${ }^{56}$ However, the activity of flexor muscles will depend on the upper system since 34 weeks of gestation. The absence of active head flexion explored by the raise-to-sit maneuver is one of the major neurological signs at 40 weeks of gestation. ${ }^{39,54,62}$

\section{What is Kurjak's Antenatal Neurodevelopmental Test (KANet)?}

Kurjak's antenatal neurodevelopmental test (KANET) is a new scoring system for the assessment of fetal neurobehavior based on prenatal evaluation of the fetus by 3D/4D US. ${ }^{65}$ It is a combination of some parameters consisting of fetal GM and of postnatal ATNAT signs, which can be easily visualized prenatally by using the 4D US, as described earlier. ${ }^{25,38}$ Before mentioned following parameters have been incorporated in the KANET test: isolated head anteflexion, overlapping cranial sutures, head circumference, isolated eye blinking, facial alterations, mouth opening (yawning or mouthing), isolated hand and leg movements and thumb position, Gestalt perception of GMs (overall perception of the body and limb movements with their qualitative assessment). ${ }^{66-73}$

Several papers have shown that there is a continuity of behavior from pre- to postnatal life and it has been observed that all movements which are present in neonates are also present in fetal life, except Moro's reflex, which cannot be demonstrated in fetuses. ${ }^{74}$ This is probably due to a different environment to which fetuses and neonates are exposed. The fetus lives in an environment of microgravity, while the newborn is exposed to full gravity, which creates certain obstacles for neurodevelopment in the first months of life. ${ }^{75-81}$ The parameters were chosen based on the developmental approach to the neurological assessment and the theory of central pattern generators of GMs emergence and were the product of multicentric studies conducted for several years. ${ }^{25,30}$ KANET is a combination of assessments of fetal behavior, GMs, and three out of four signs which have been postnatally considered as symptoms of possible neurodevelopmental impairment (neurological thumb, overlapping sutures, and small head circumference). ${ }^{82-85}$

KANET test has been standardized, it is reproducible and easily applied by fetal medicine specialists. ${ }^{85,86-88}$ KANET should be performed in the 3rd trimester of pregnancy, between 28 and 38 weeks. The duration of the examination should last between 15 and 20 minutes, and fetuses should be examined while they are awake. If the fetus is in the sleeping period, the assessment should be postponed for 30 minutes or the following day, at a minimum period of 14-16 hours. In cases of a grossly abnormal or borderline score, the test should be repeated every 2 weeks until delivery. Special attention should be paid to the facial movements and to eye blinking, which is prenatally very informative and important ("the face is the mirror of the brain"). The overall number of movements should be defined in very active or inactive fetuses and compared with normal values of previous studies ${ }^{25,30}$ (Figs 5 and 6).

All the examiners should have extensive hands-on education for the application of the KANET test, both in low- and high-risk pregnancies. Inter-and intraobserver variability should be available. It is advisable to use 4D US machines, with a frame rate of a minimum of 24 volumes/second. KANET consists of eight parameters (Table 3).

A score range of $0-5$ is characterized as abnormal, a score calculated from 6 to 13 is considered borderline and a score range of 14-20 is normal (Table 4). After that neonates should be followed up postnatally for neurological development for 2 years.

The test evaluates quantitative as well as qualitative aspects of fetal motor behavioral patterns. The parameters examined by this test are a combination of GMs and parameters adopted from ATNAT. ${ }^{89,90}$ The criterion of quality and quantity of spontaneous GMs is believed to have excellent reliability in evaluating the integrity of fetal CNS. ${ }^{91,92}$ Furthermore, continuity of behavioral patterns 

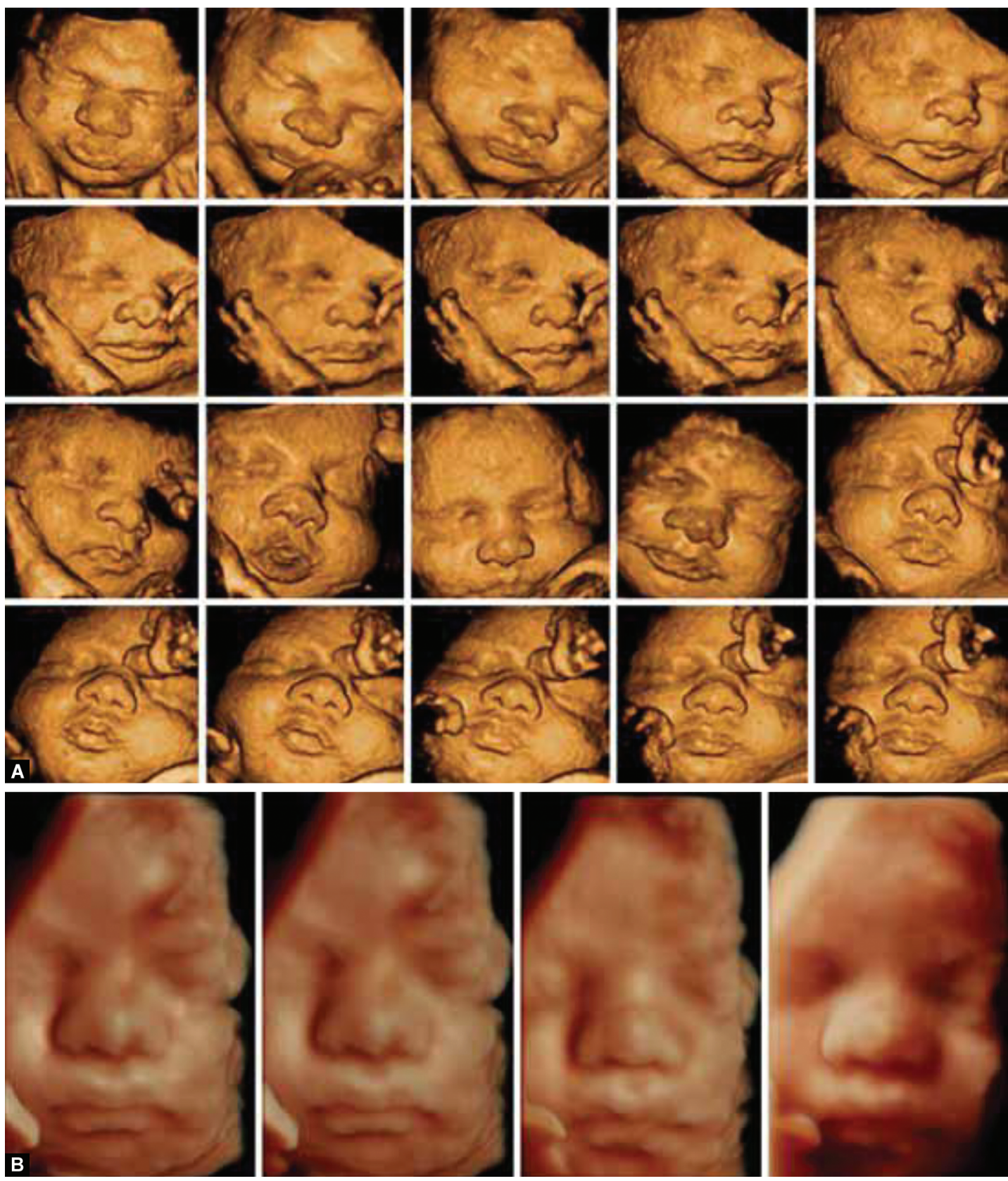

Figs 5A and B: (A) Normal KANET score at 34 weeks of pregnancy; (B) Normal KANET score at 32 weeks of pregnancy-the impact of the evolution of ultrasound technology on the quality of fetal assessment

from prenatal to the postnatal period has been proven. . $^{27,93,94}$ Both those facts justify the choice of the parameters used in this test, making KANET theoretically appropriate for the assessment of fetal behavior. According to previous reports, ${ }^{28,29,95-98}$ KANET easily recognizes serious functional impairment associated with structural abnormalities. Studies have shown that the application of KANET in both low- and high-risk populations has given good results and especially in high-risk populations, KANET may provide useful information regarding the neurological outcome of these fetuses. ${ }^{99}$ KANET is the first test which is based on the 4D US, with an original scoring system and has been standardized, so it can be implemented in everyday practice, overcoming the difficulties and covering the gaps of methods that were used in the past for the evaluation of fetal behavior. ${ }^{16,100-102}$ Studies show that KANET is easily applicable to most pregnancies, the learning curve is reasonable for physicians who already have training in obstetrical ultrasound and the actual duration of KANET ranges from 15 to 20 minutes, showing strong evidence that it can be widely implemented in everyday clinical practice. ${ }^{98}$

KANET has been introduced in training and has been calculated that the number of KANET tests needed to be performed by an experienced ultrasound specialist to be familiar to assess a fetus with the 4D US in 20 minutes is 80 . The success rate of the test ranges from 91 to $95 \%$ and further study of each parameter reviled a success rate for the assessment of particular signs of $88 \%$ for isolated eye blinking and $100 \%$ for mouth opening and isolated 

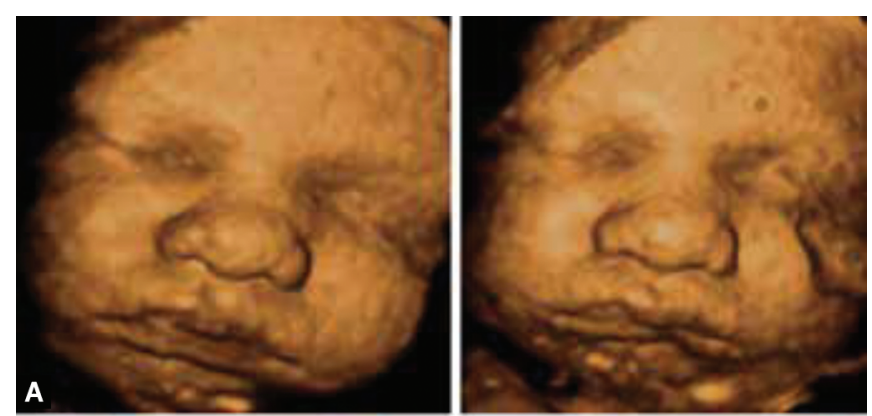

leg movement. KANET has almost $100 \%$ negative predictive value, interobserver variability was satisfactory with the lowest being for the facial expression $(K=0.68)$ and highest for the finger movements $(K=0.84)$.

\section{What have Studies about KANET Shown So Far?}

One of the first studies to use a preliminary form of the KANET scoring system was that by Andonotopo and Kurjak in $2006 .^{29}$ They aimed to assess fetal facial expression and quality of body movements and examine if they are of diagnostic value for brain impairment in fetuses with growth restriction. In that prospective study of 50 pregnancies with IUGR fetuses in the 3rd trimester of pregnancy, a tendency of less behavioral activity in IUGR than normal fetuses has been noted. The results of the study encouraged the future investigation of the use of 4D US for quantitative and qualitative assessment of fetal behavior as possible indicators of the neurological condition in IUGR fetuses. ${ }^{29}$

The Zagreb group in 2008 was the first to introduce the KANET for the assessment of the neurological status of the fetus, aiming to the detection of the fetal brain and neurodevelopmental alterations due to in utero brain impairment. ${ }^{27}$ To develop the new scoring system they identified severely brain-damaged neonates and neonates with a good neurological condition and then compared the neonatal findings, with corresponding findings in utero. In the group of 100 low-risk pregnancies, they retrospectively applied KANET. After delivery, postnatal neurological assessment (ATNAT) was performed and all neonates assessed as normal reached a score between 14 and 20, assumed to be the score of optimal neurological development. A new scoring system was applied in the group of 120 high-risk pregnancies in which, based on postnatal neurological findings, three subgroups of newborns were identified: normal,

Figs $6 \mathrm{~A}$ to $\mathrm{C}$ : Face grimacing findings, th

Table 3: Proposal for the new KANET assessment tool consisting of eight parameters

\begin{tabular}{llll}
\hline & \multicolumn{3}{c}{ Score } \\
\cline { 2 - 4 } Sign & 0 & 1 & 2 \\
\hline Isolated head anteflexion & Abrupt & $\begin{array}{l}\text { Small range }(0-3 \text { times of } \\
\text { movements })\end{array}$ & $\begin{array}{l}\text { Variable in full range, many } \\
\text { alternations }(>3 \text { times of } \\
\text { movements })\end{array}$
\end{tabular}

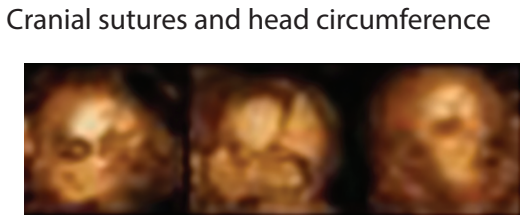

Isolated eye blinking

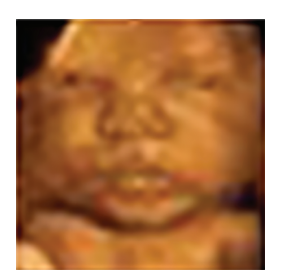

Overlapping cranial Normal cranial sutures sutures

Not present with measurement of FX below or above the normal limit (-2 SD) according to GA

Not fluent $(1-5$ times of blinking)
Normal cranial sutures with normal measurement of $\mathrm{HC}$ according to $\mathrm{GA}$

Fluency ( $>5$ times of blinking) 
Contd...

\begin{tabular}{llll}
\hline \multirow{2}{*}{ Sign } & \multicolumn{3}{c}{ Score } \\
\cline { 2 - 4 } $\begin{array}{l}\text { Facial alteration (grimace or tongue } \\
\text { expulsion) }\end{array}$ & Not present & $\begin{array}{l}\text { Not fluent (1-5 times of } \\
\text { alteration) }\end{array}$ & $\begin{array}{l}\text { Fluency (1-5 times of altera- } \\
\text { tion) }\end{array}$ \\
& & & \\
& & &
\end{tabular}

or

Mouth opening (yawning or mouthing)

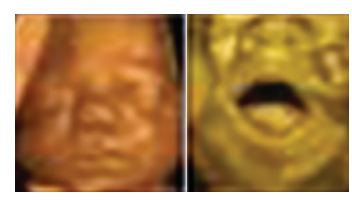

Isolated leg movement

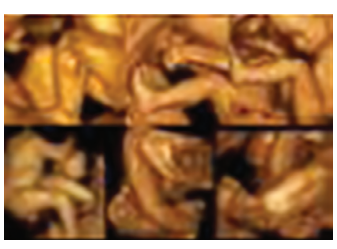

Isolated hand movement

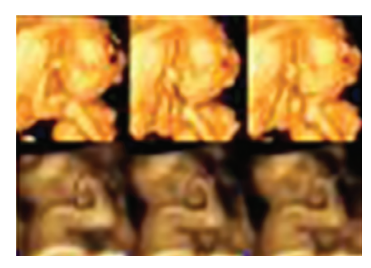

or

Hand to face movements

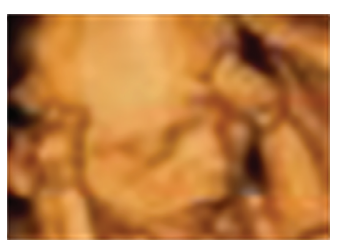

Fingers movements

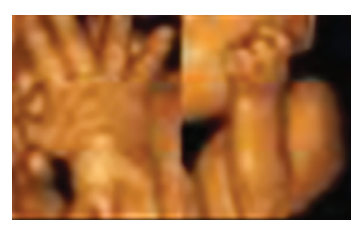

Cramped

Cramped or abrupt

Po or repertoire or small in range (0-5 times of movement)

Po or repertoire or small in range $(0-5$ times of movement)

Variable in full range, many alternations ( $>5$ times of movements)

Variable in full range, many alternations ( $>5$ times of movements)
Unilateral or Cramped invariable

bilateral clenched finger movements
Smooth and complex, variable

\section{finger movements} thumb) 
Table 4: Interpretation of KANET scores

\begin{tabular}{ll}
\hline Total score & Interpretation \\
\hline $0-5$ & Abnormal \\
$6-9$ & Borderline \\
$10-16$ & Normal \\
\hline
\end{tabular}

Stanojevic et al. "Osaka Consensus Statement" DSJUOG 2011;5:4 pp. 317329

mildly or moderately abnormal, and abnormal. ${ }^{30}$ Based on this, a neurological scoring system has been proposed. All normal fetuses reached a score from 14 to 20 . Ten fetuses who were postnatally described as mildly or moderately abnormal achieved a prenatal score of $5-13$, while another 10 fetuses postnatally assigned as neurologically abnormal had a prenatal score of $0-5$. Among this, group 4 had alobar holoprosencephaly, one had severe hypertensive hydrocephaly, one had thanatotrophic dysplasia, and four fetuses had multiple malformations. This study inspired a large series of multicenter studies (Table 5) that used the KANET to assess the usefulness of this promising new scoring system for the assessment of neurological status in fetuses and the recognition of signs of early brain impairment in utero. ${ }^{106,107}$

The first application of KANET was on growth-restricted fetuses, ${ }^{29}$ where mainly facial expressions and body movements were studied, and what was noticed was a decreased behavioral activity in the IUGR fetuses compared to normal growth cases. The study that followed was the first with complete neurologic postnatal assessment for all studied fetuses and according to the criteria they used neonates were divided into three groups: normal, mildly or moderately abnormal, and abnormal. According to these groups, the formation of the first KANET scoring system was decided which was as follows: 14 to 20 (normal), 5 to 13 (mildly or moderately abnormal), and 0 to 5 (abnormal) and based on this scoring system where all the following studies designed. ${ }^{106,107}$

The first study with a large number of high-risk pregnancies identified 32 fetuses at neurological risk: they identified 7 cases with abnormal scores and 25 with a borderline KANET score. There were also 11 cases that either died in utero or had a termination of pregnancy and all of these cases had an abnormal KANET score. The 7 remaining neonates with abnormal KANET were followed up postnatally at 10 weeks of neonatal life and 3 had confirmed pathological ATNAT score. These 3 cases included a neonate with arthrogryposis, a neonate with cerebellar vermian complete aplasia, and 1 case with a history of $C P$ in a previous pregnancy. Out of the parameters that KANET uses, facial expressions appeared to be most pathological - the fetal faces were characterized as "masks" by the authors, due to lack of expressions on 4D ultrasound. The remaining 4 pathological KANET cases had a normal postnatal assessment. These 4 cases, however, had complications of pregnancy: 1 case with ventriculomegaly, 1 case with preeclampsia, 1 case with maternal thrombophilia, and 1 case with oligohydramnios. From the 25 cases diagnosed with borderline KANET result, 22 neonates showed a borderline ATNAT score and were followed up, while the 3 remaining cases showed normal ATNAT results. An interesting paper was the one that studied a case of a fetus with prenatally diagnosed acrania. The authors studied fetal behavior and managed to document how it altered from 20 weeks of gestation onward. It was noticed that as pregnancy progressed and the control center of motoric activity shifted from the lower to the upper part, KANET score was decreasing, respectively, suggesting that neurological damage in later pregnancy is possible. ${ }^{95}$
A study with 226 cases, including different study populations, identified 3 cases with pathological KANET scores. ${ }^{98}$ All 3 cases had chromosomal abnormalities and all 3 of them postnatally also had an abnormal ATNAT score. Scores from antenatal KANET and postnatal ATNAT were compared between low- and high-risk groups, and showed differences between them, for 8 out of the 10 parameters - these included: head anteflexion, eye blinking, facial expressions-grimacing, tongue expulsion, mouth movements such as yawning, jawing, swallowing -isolated hand movements, hand-to-face movements, fist-and-finger movements, and GMs (Table 6).

The comparison of the two tests revealed a correlation between them, proving that the neonatal exam (ATNAT) was a satisfactory confirmation of the prenatal ultrasound examination (KANET), stating that KANET could offer useful information about the neurological status of the fetus and can be applied in clinical practice.

One of the largest studies regarding $\mathrm{KANET}^{97}$ including 620 cases, of both low- and high-risk populations (100 low-risk and 520 high-risk cases) showed differences in the scores between the two groups. What was interesting in this study was that most abnormal cases were noted from pregnancies with a previous history of CP (23.8\%) and that most borderline scores were noted in cases with possible chorioamnionitis (56.4\%). The parameters of KANET that were more notably different between the two groups were: overlapping cranial sutures, head circumference, isolated eye blinking, facial expressions, mouth movements, isolated hand movements, isolated leg movements, hand-to-face movements, finger movements, and GMs. This study confirmed the relationship of pathological KANET with increased risk of perinatal mortality and neurological impairment and showed that the results can be confirmed and are reproducible postnatally.

A recent study with a complete follow-up ${ }^{108}$ postnatally up to 3 months of life, with complete postnatal documentation in all cases and showed that a normal KANET score is very reassuring of a good neonatal outcome, confirming the consistency of prenatal and postnatal assessment. Understanding the evolution of fetal movements by 4D ultrasound throughout pregnancy, and how these movements reflect the development and integrity of the fetal nervous system was a great challenge. What was shown was that during the first weeks of pregnancy the development of the frequency and the complexity of fetal movements is more important, while during the second trimester the variation of fetal movements develop, with more detailed movements (facial expressions and eye blinking) appearing at the end of this trimester. Finally, at the end of the third trimester, the number of fetal movements declines as a result of the increase of fetal rest periods, due to fetal cerebral maturation, and this is something that most pregnant women notice near term. ${ }^{86,106,109}$ A very interesting study that tried to shed some light on the clinical dilemmas caused by the prenatal diagnosis of ventriculomegaly, compared fetuses with ventriculomegaly ${ }^{99}$ with apparently low-risk fetuses (normal CNS appearance on ultrasound examination). A significant difference was noted between the two groups, with the KANET score decreasing as the degree of ventriculomegaly was increasing. For isolated cases of mild or moderate ventriculomegaly, no pathological KANET scores were noted and postnatal evaluation confirmed the prenatal KANET, offering valuable information for the more complete assessment of these fetuses and better counseling regarding their prognosis. 


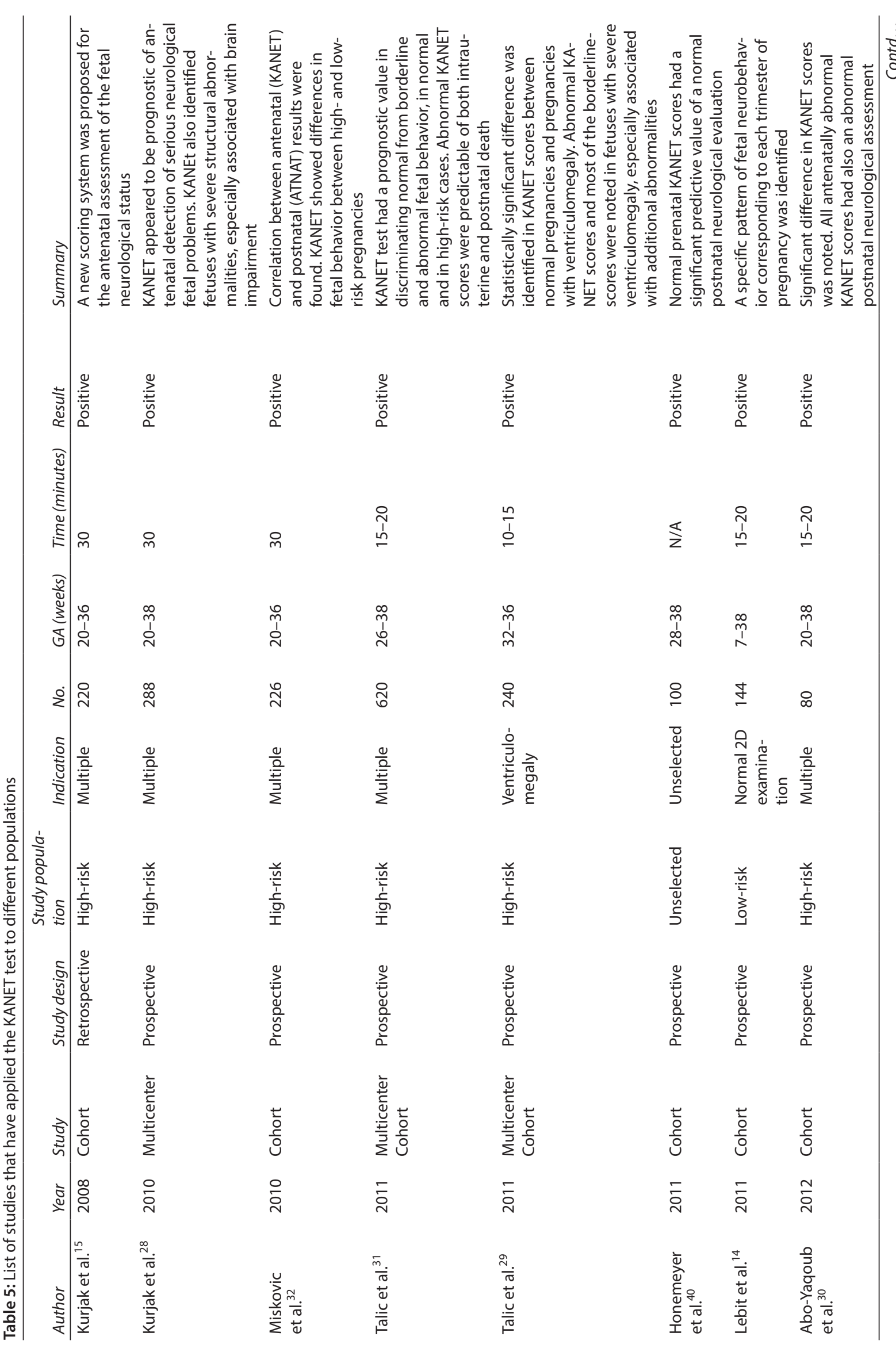




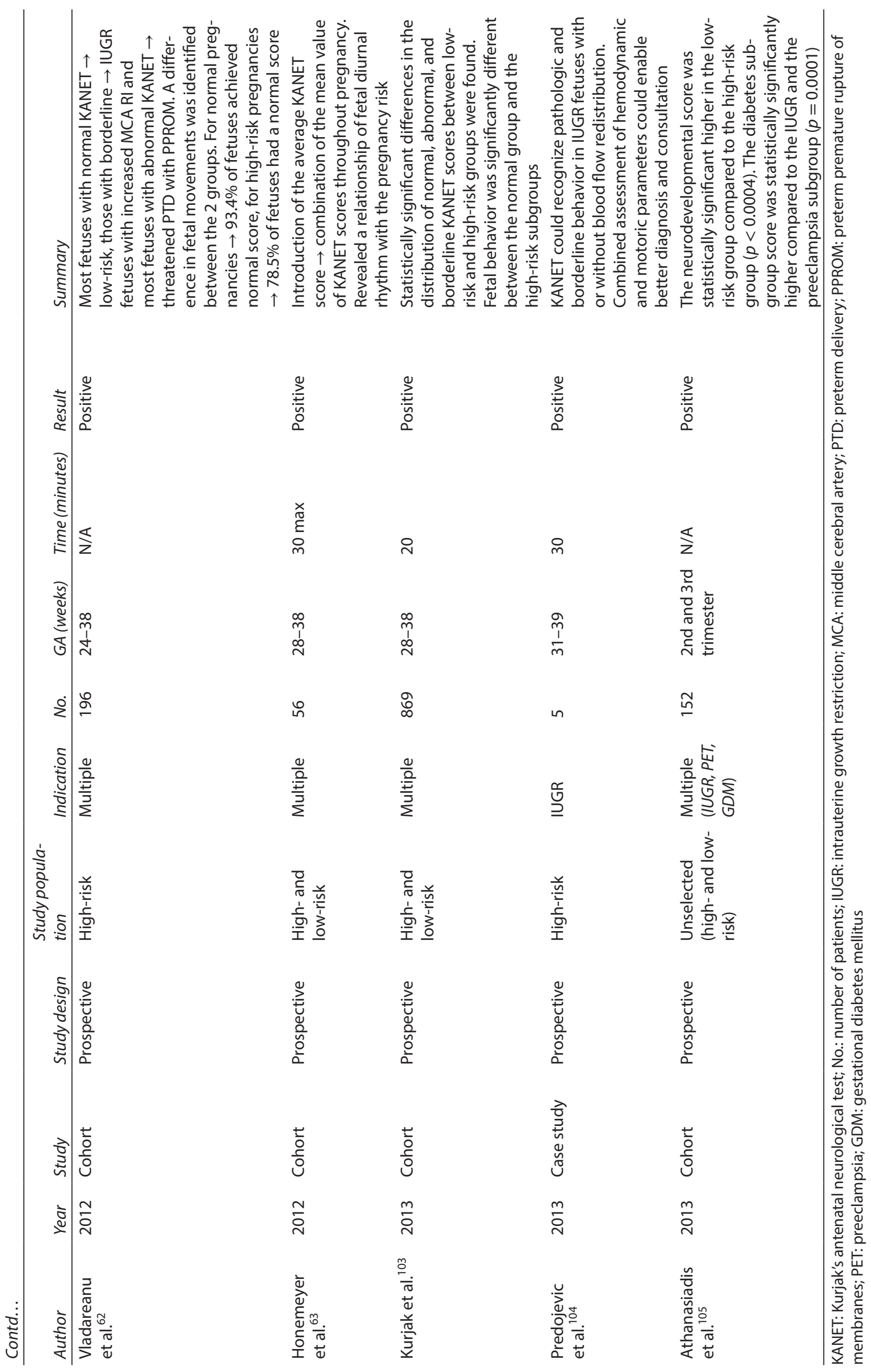




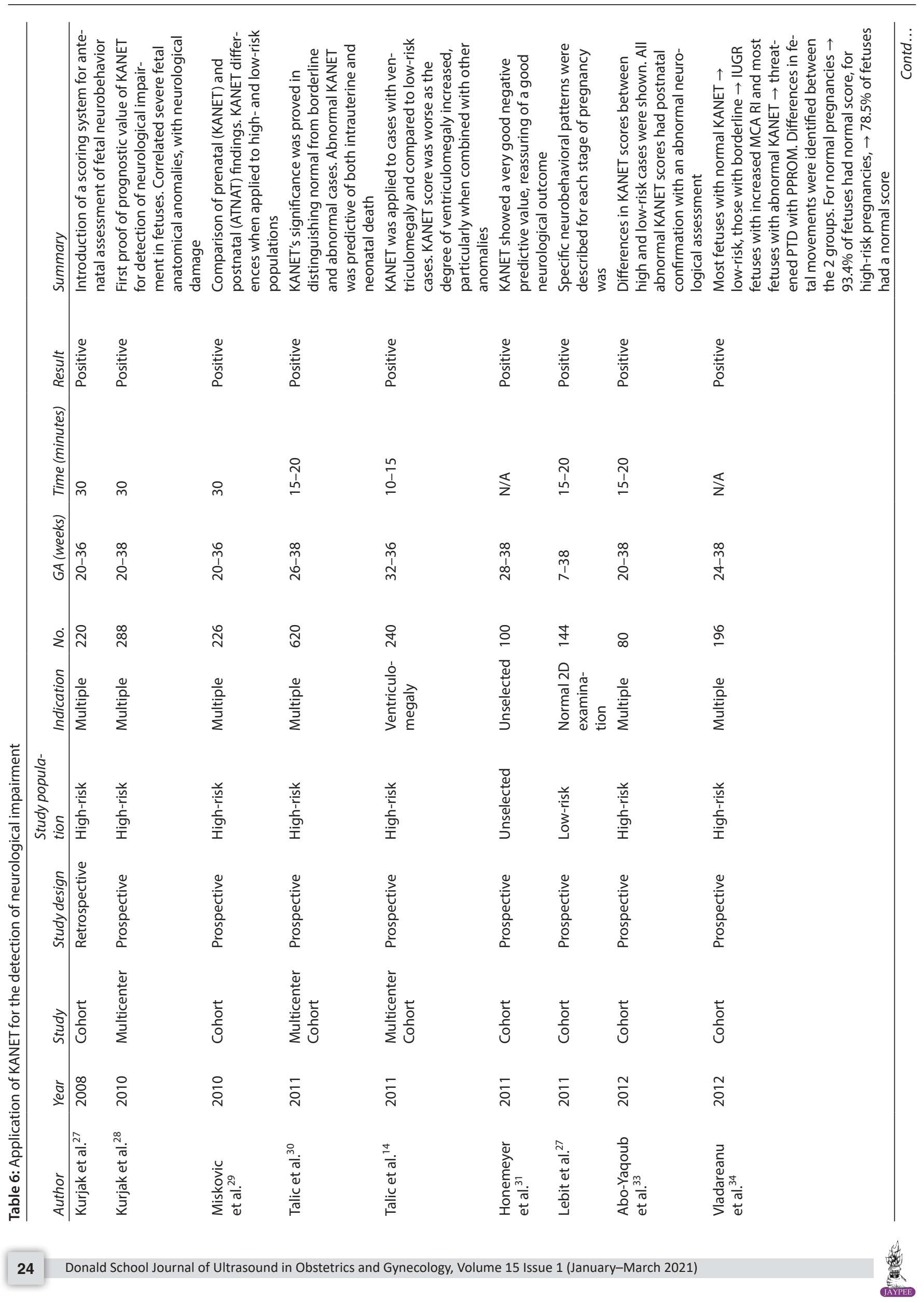




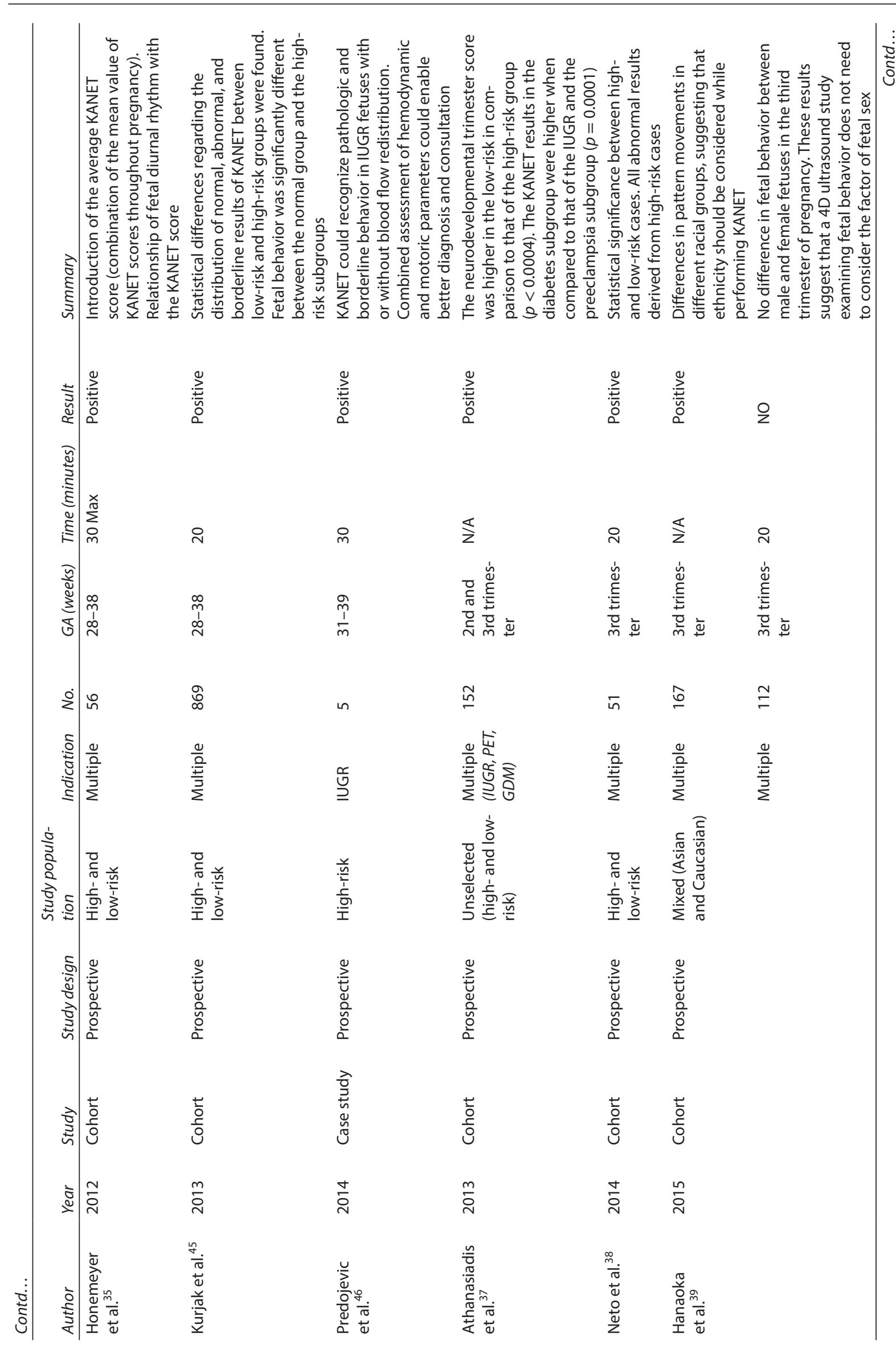




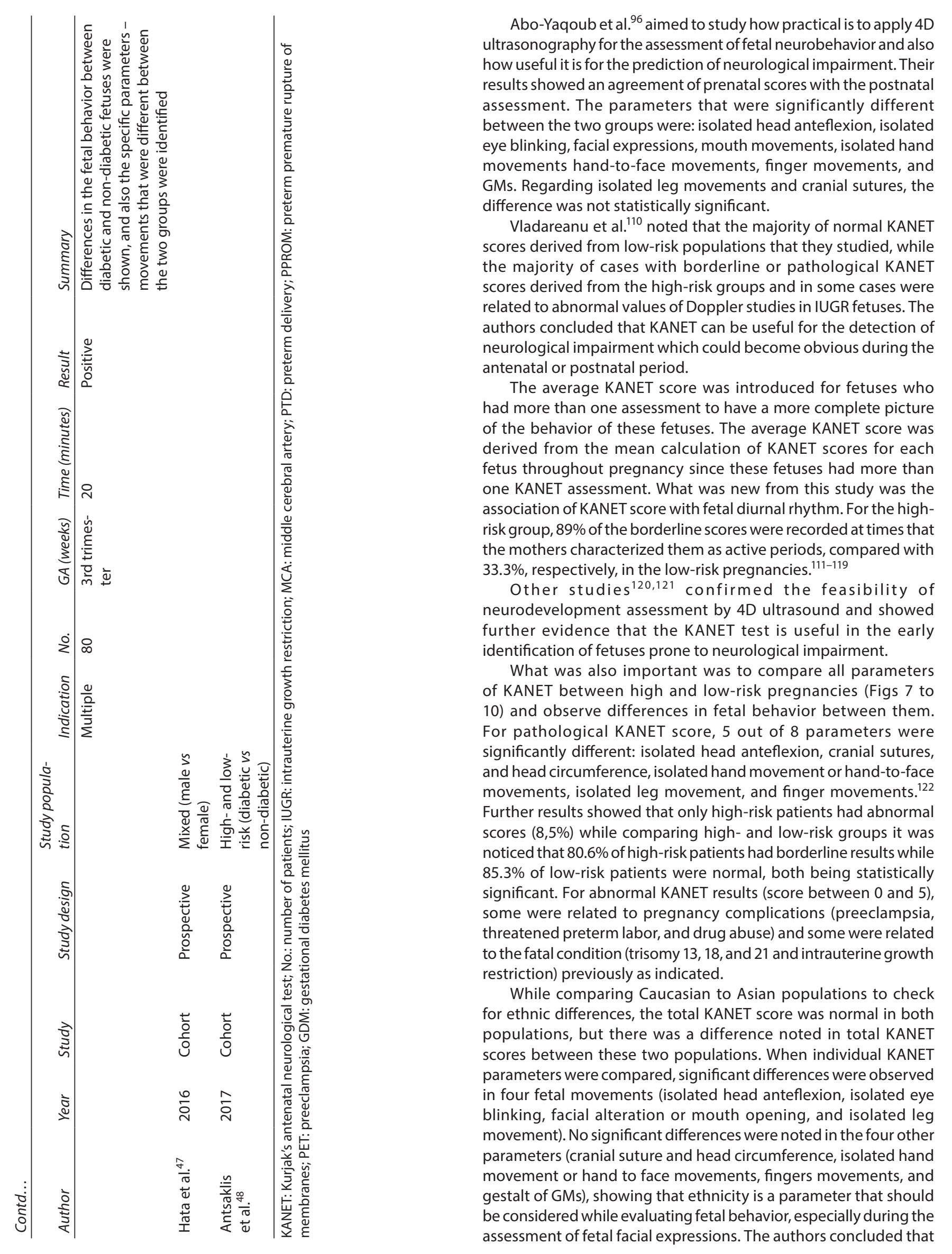



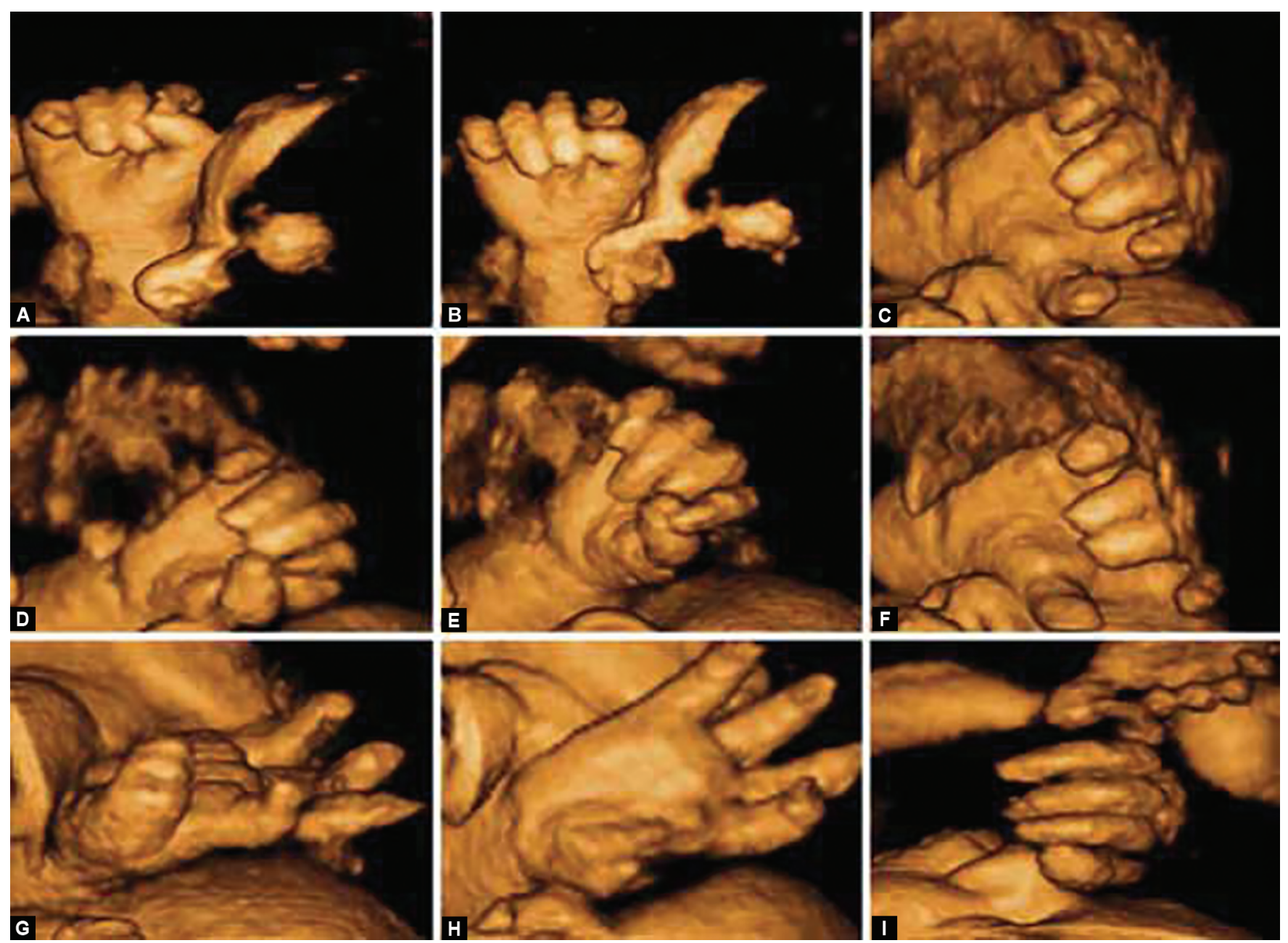

Figs 7A to I: Hand and finger movement

although there was a difference in the total KANET score between Asian and Caucasian populations, all the scores in both groups were within the normal range proving that ethnical differences in fetal behavior do not affect the total KANET score, but close follow-up should be continued in some borderline cases. ${ }^{123}$

Unpublished data from Greece, from 655 singleton pregnancies, showed that KANET is a method that is feasible in everyday clinical practice, with a success rate of $95 \%$ and a very low negative predictive value. For the cases that KANET could not be completed, the reason was severe oligohydramnios, fibroid uterus (difficult imaging), very increased BMI, and a case that due to vasovagal reaction-supine hypotensive syndrome ultrasound examination could not be completed. From the 655 cases, 1,712 KANET were performed from only two operators and the interobserver variability was calculated showing adequate results for all parameters, with the lowest being for facial alterations ( $k$-value $=$ 0.68 ) and the highest for finger movements ( $k$-value $=0.84)$. This study was primarily designed to compare the neurological status of pregnancies complicated by diabetes, compared to low-risk pregnancies and it did show that there was a difference between the fetal neurobehavior of these two groups, with the diabetic pregnancies having lower scores. ${ }^{124}$

Figures 11 to 13 are illustrating important parameters of KANET depicted by high definition (HD) 4D US.

\section{Interpretation of KANET Test esearch}

One of the greatest challenges in perinatal medicine is the assessment of fetal neurobehavior and detection of fetal neurological impairment in utero. KANET is the first method that applied 4D ultrasound for the assessment of the fetus in the same way that a neonate is assessed neurologically after birth by neonatologists and it appears to be a strong diagnostic method for the detection of neurological impairment and for the assessment of fetal neurobehavior, conditions that were inaccessible with the traditional prenatal diagnostic methods used so far. ${ }^{74}$ Studies have proved the validity of this method, ${ }^{27,28,86}$ its applicability in everyday clinical practice, especially for high-risk cases, how and by whom it should be performed, and what is the value of the result of KANET and how it should be managed. Diagnosis of neurological impairment prenatally is very difficult and usually, all these diagnoses are made postnatally, even months or years after delivery. What is more neurological conditions, such as CP are not adequately understood and falsely attributed to incidents during labor, although it has been proven that the majority of $\mathrm{CP}$ cases originate sometime during in utero life and are not related to intrapartum events. All these things lead to delayed diagnosis of neurological conditions. The later a neurological impairment is diagnosed the less is the possibility of an effective intervention. 

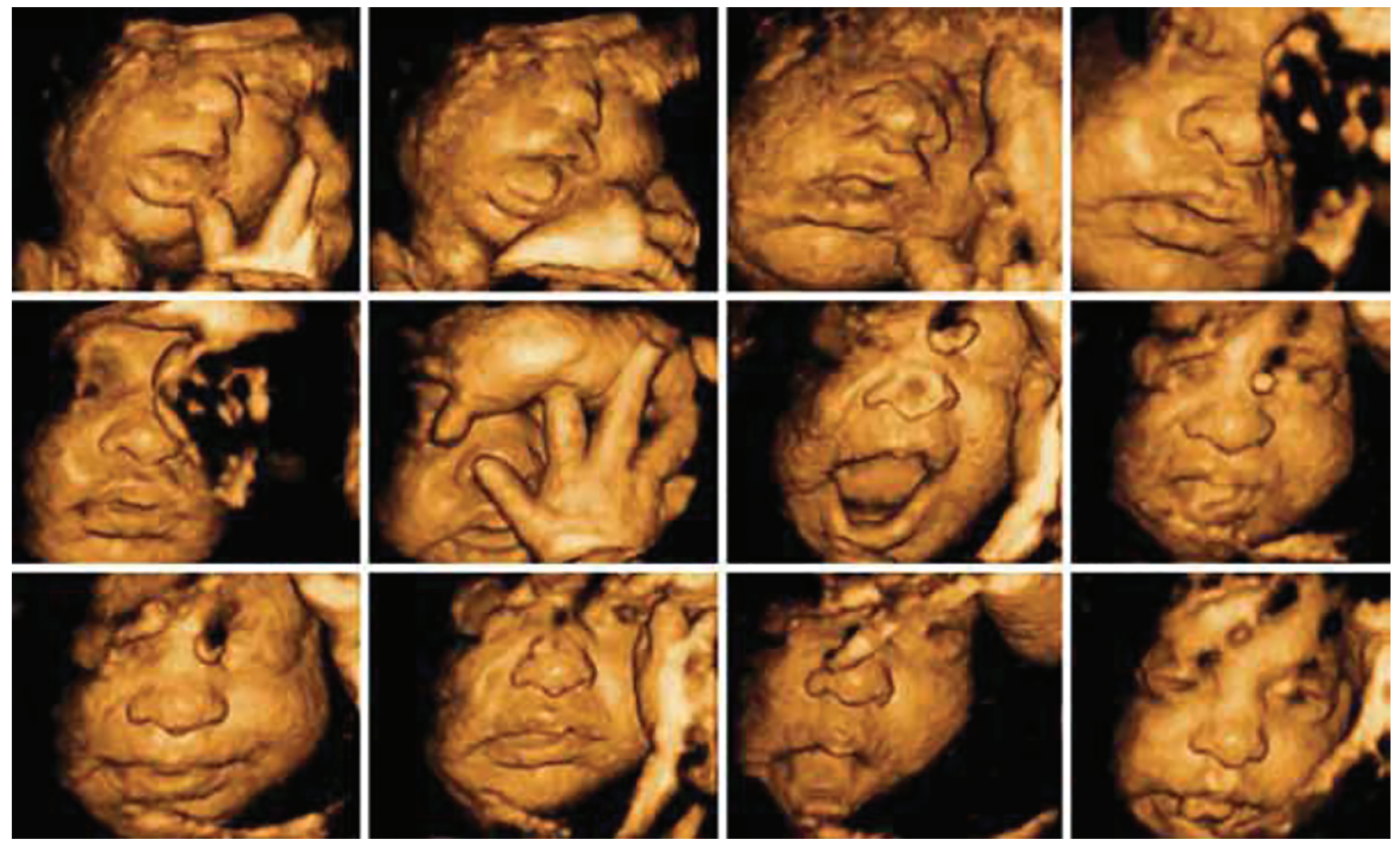

Fig. 8: KANET—facial alterations mouthing, eye blinking and hand movement
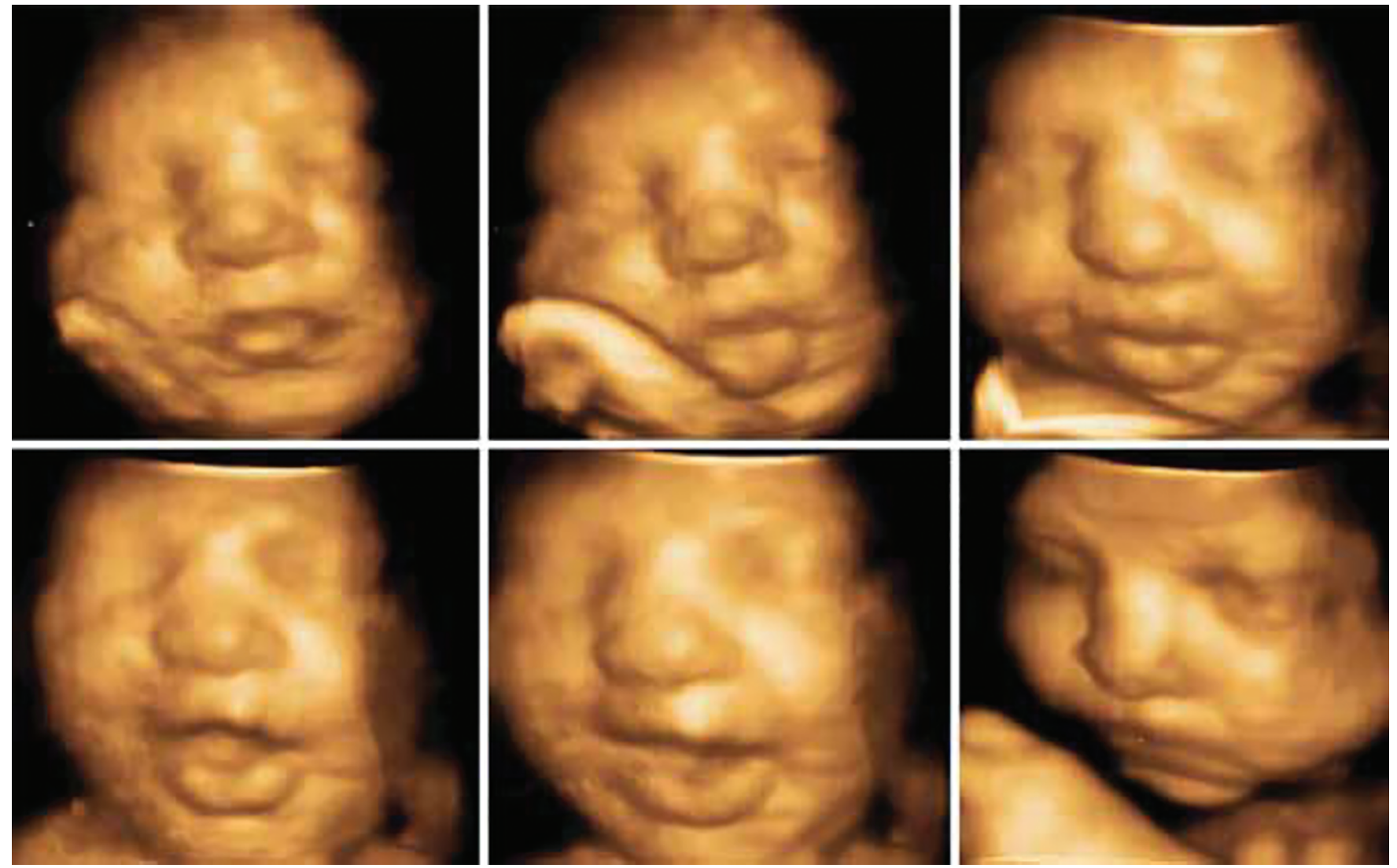

Fig. 9: Tongue expulsion and mouthing 

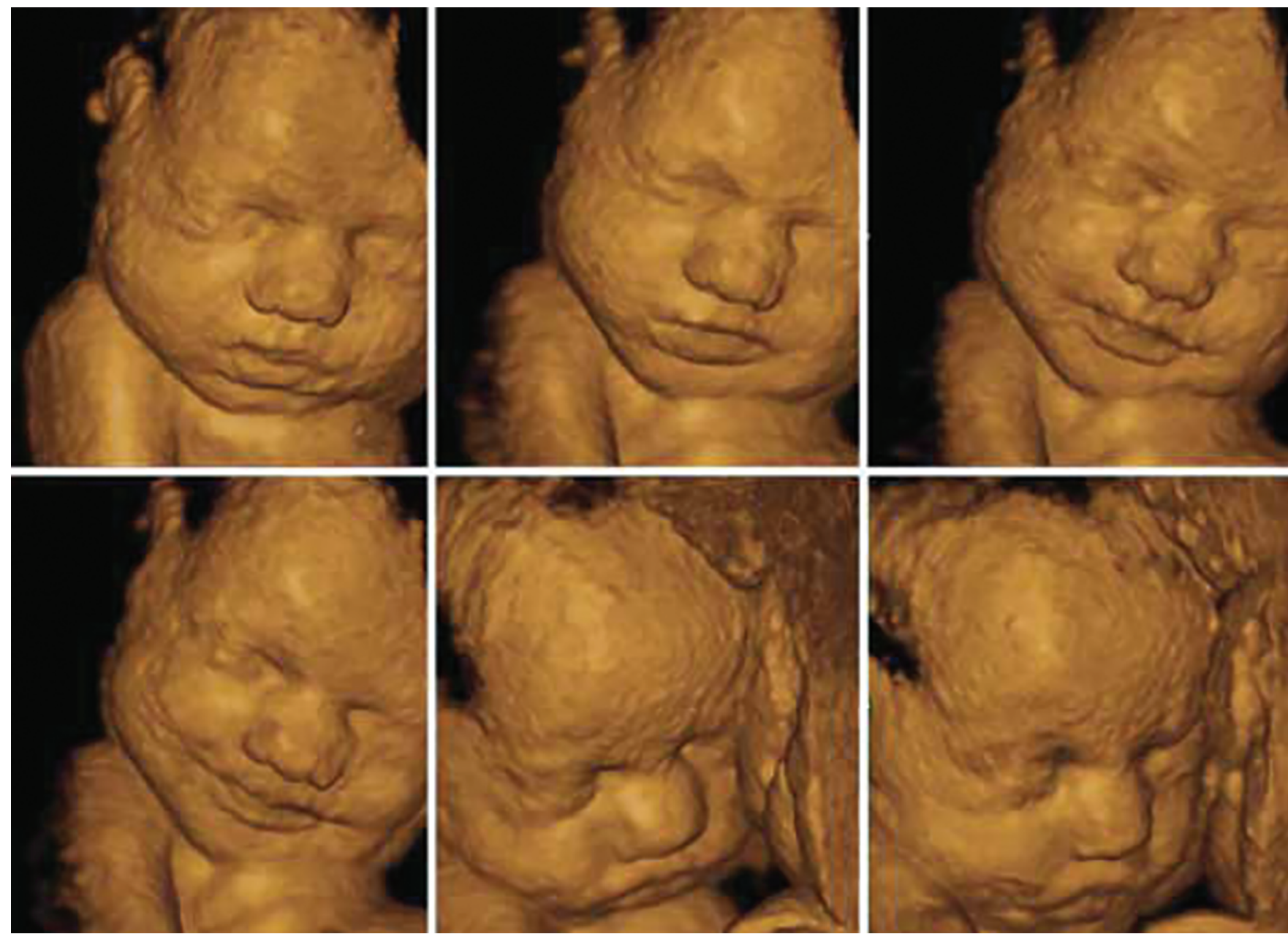

Fig. 10: Smiling
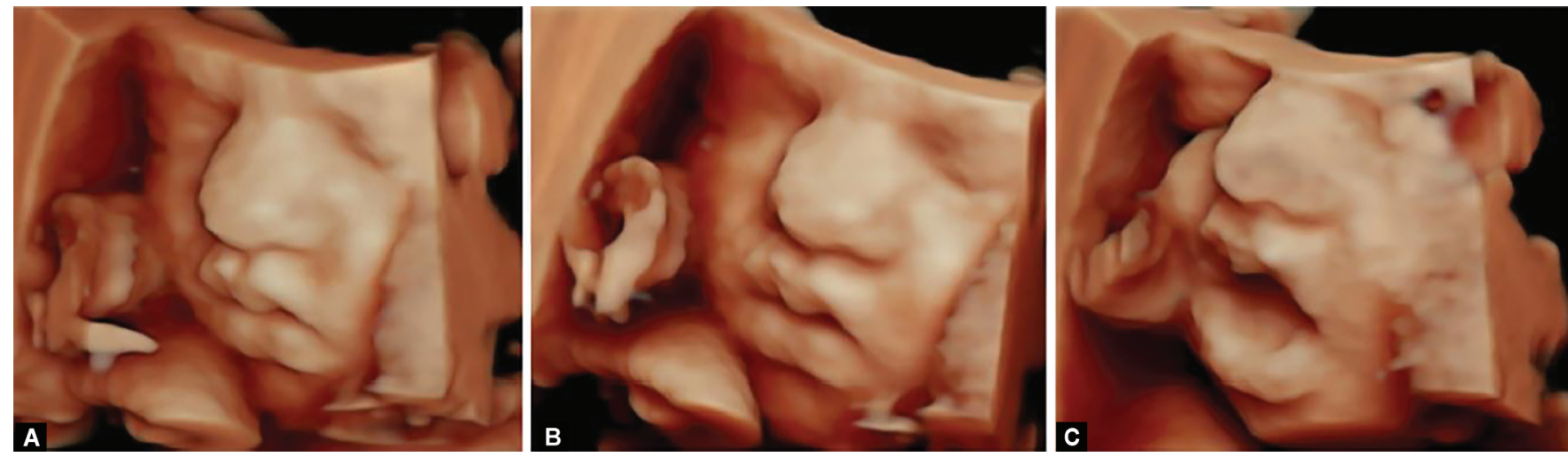

Figs $11 \mathrm{~A}$ to $\mathrm{C}$ : Mouthing as part of the assessment of fetal neurobehavior (High definition 4D US)

It would be extremely challenging to have a timely diagnosis of such conditions, even during in utero life, to increase the possibility of an effective intervention or even treatment. KANET offers the possibility of prenatal detection of fetuses at risk for neurological problems, offering the possibility of even an in utero intervention or at least an early postpartum intervention. ${ }^{125}$ The earliest physiotherapy is commenced and intervention programs are applied in neonates that are born prematurely or with neurological problems the better the neurodevelopmental outcome of these neonates, with the cognitive benefits persisting into pre-school age. KANET appears to be able to offer this advantage of early identification of these fetuses with neurological problems, so that they could be put under treatment as early as possible, aiming for a better outcome. ${ }^{120,126}$

What is more, the explicitly detailed pictures obtained by the new ultrasound machines but also the advanced techniques of molecular genetics, many times brings us, as ultrasound specialists, across findings (anatomical and chromosomal) of 


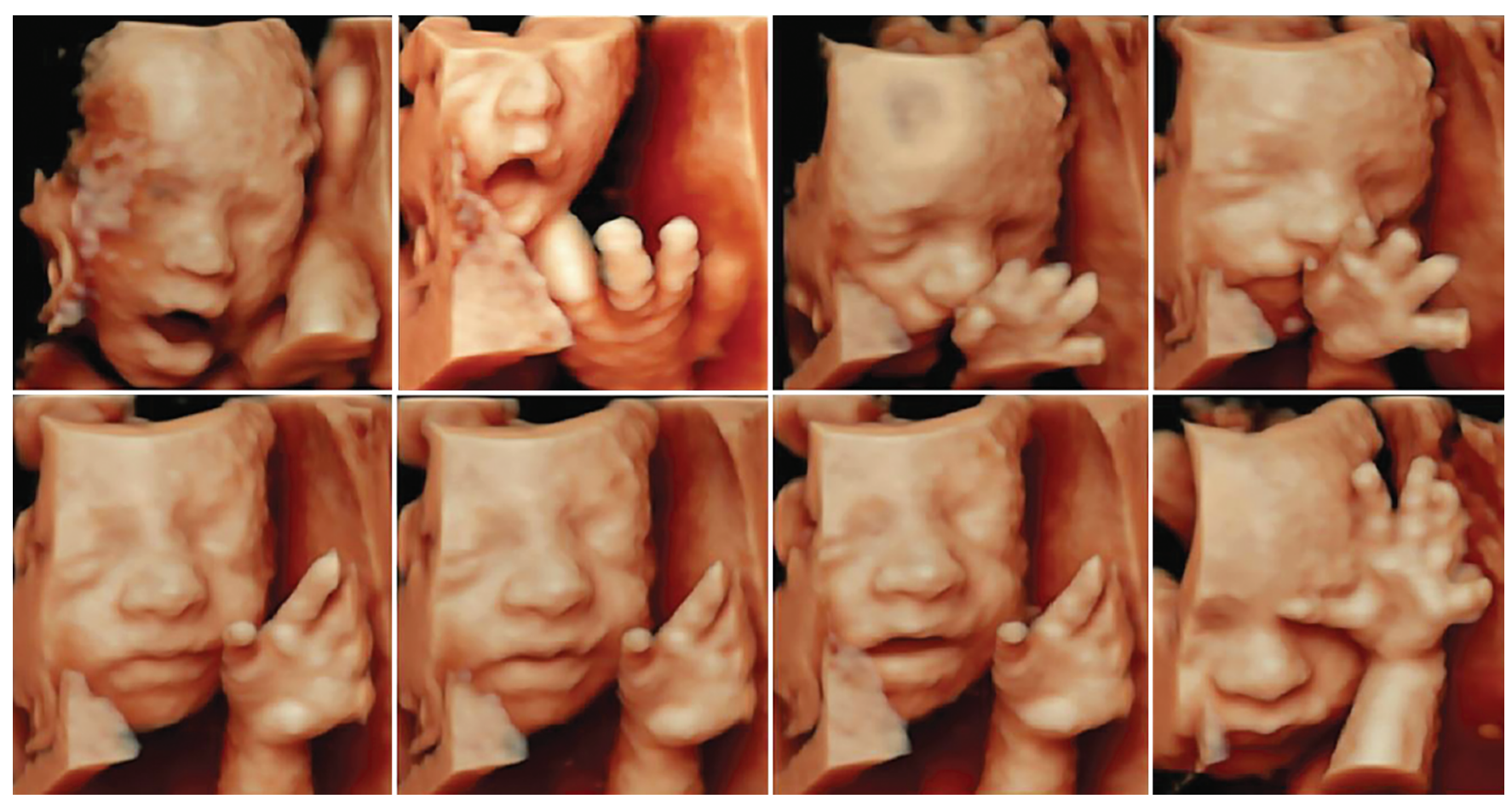

Fig. 12: Parameters of Kurjak's antenatal neurodevelopmental test (KANET) test: mouthing, yawning, and hand movements (High definition 4D US)
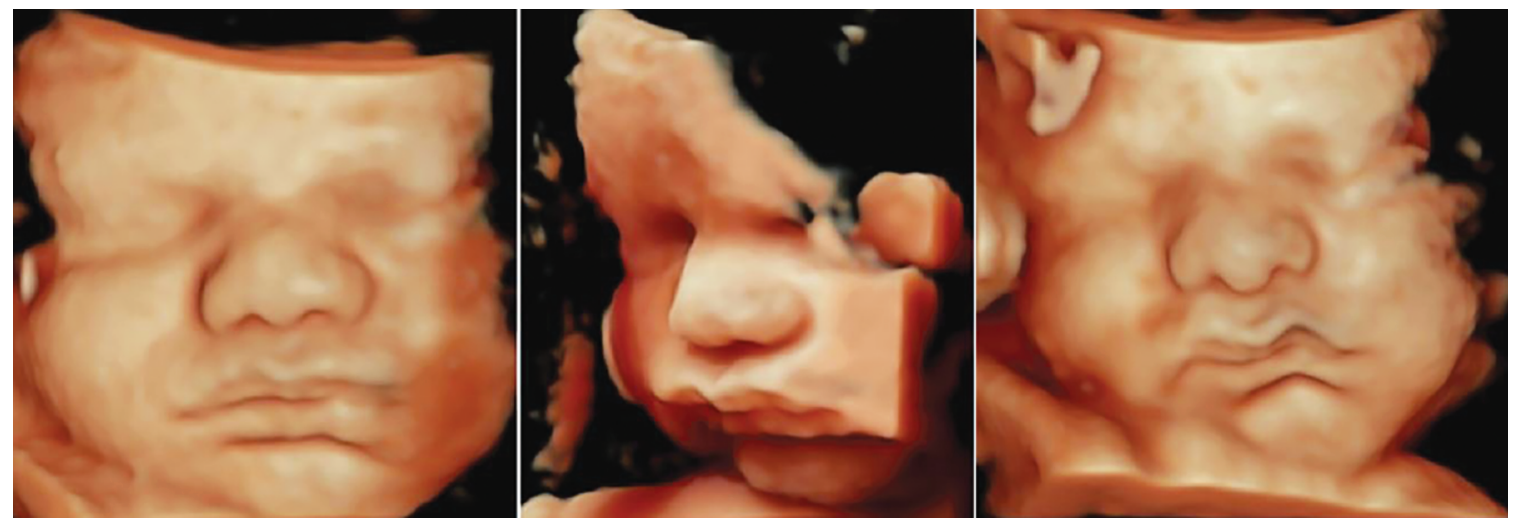

Fig. 13: Facial expression and grimacing (High definition 4D US)

uncertain clinical significance and prognosis, especially regarding the neurological integrity of the fetus. ${ }^{127-129}$ A method like KANET offers a more comprehensive diagnostic approach to such dilemmas and hopefully soon with more data we could form a complete neurosonobehavioral assessment of the fetus and more complete counseling of these couples. ${ }^{130}$

KANET has currently been introduced in everyday clinical practice by many centers for the assessment of fetal neurobehavior of not only high-risk cases but also low-risk pregnancies. Studies show that the sensitivity and specificity of the test are satisfactory, as are the positive and negative predictive values and the interand intraobserver variability of this method. The KANET has been introduced into systematical training and already ultrasound specialists have been certified to perform this examination. Hopefully, the application of KANET on larger populations, both high- and low-risk, will give more knowledge regarding early detection of fetuses at risk for neurological impairment, allow accurate diagnosis prenatally, and as a consequence prompt intervention that could possibly improve the outcome of some of these neonates.

\section{The Most Recent Research Data on the KANET TEST}

The data of fetal prenatal neurological testing from nine centers by nine investigators from seven countries were performed from May 2010 till April 2020, with the number of 25 to 1,344 fetuses from singleton pregnancies are presented. ${ }^{131}$ Altogether there were 3,709 fetuses of whom 1,573 (42.4\%) completed the pregnancy of which 1,556 were eligible for postnatal follow-up, while in 2,136 mostly low-risk pregnancies for 2,094 the data were missing while in 42 the pregnancies were still ongoing (Table 7). From the group of 3,709 fetuses, 3,206 (86.5\%) had normal, 379 (10.2\%) borderline, and $124(3.3 \%)$ abnormal KANET scores, respectively, while in those 
after completed pregnancy 153 (9.7\%) had borderline and 52 (3.3\%) had abnormal KANET scores (Tables 7 and 8).

The inter-rater reliability was substantial for low-risk pregnancies and moderate for high-risk pregnancies. There were 2,502 (67.5\%) fetuses from low-risk pregnancies and 1,207 (32.5\%) fetuses from high-risk pregnancies (Table 8). Fetuses from high-risk pregnancies had higher frequencies of borderline and abnormal KANET scores compared to the fetuses from low- risk pregnancies, which was statistically significant. It could be speculated that a hostile intrauterine environment is affecting adversely fetal neurobehavior, which can be detected by the KANET test. The dropout rate in the investigation was high (47.6\%), respectively, which is a severe constraint of the investigation. Most of the dropouts were from low-risk pregnancies with low rates of borderline or abnormal KANET scores and a high probability of normal postnatal development.

Table 7: The results of the KANET ${ }^{+}$test from nine centers: the date of the introduction of KANET, number of patients investigated, total number of borderline and abnormal scores, number with postnatal follow-up, number of borderline and abnormal cases in all fetuses and those postnatally followed-up

\begin{tabular}{|c|c|c|c|c|c|c|c|}
\hline \multirow[b]{3}{*}{ Name of the investigator/country } & \multirow[b]{3}{*}{ Introduction of KANET ${ }^{+}$} & \multirow{3}{*}{$\begin{array}{l}\text { Number } \\
\text { of fetuses }\end{array}$} & \multirow{2}{*}{\multicolumn{2}{|c|}{$\begin{array}{c}\text { All fetuses } \\
K A N E T^{+} \text {scores }\end{array}$}} & \multicolumn{3}{|c|}{ Postnatal follow-up } \\
\hline & & & & & \multirow{2}{*}{$\begin{array}{l}\text { Number of } \\
\text { children }\end{array}$} & \multicolumn{2}{|c|}{$K^{\prime} A N E T^{+}$scores } \\
\hline & & & Borderline & Abnormal & & Borderline & Abnormal \\
\hline Lara Spalldi Barisic, Croatia* & May, 2010 & 1,344 & $98(7.3 \%)$ & $52(3.9 \%)$ & $482(35.9 \%)$ & $36(7.5 \%)$ & $19(3.9 \%)$ \\
\hline Panos Antsaklis, Greece ${ }^{19}$ & January, 2012 & 1,180 & $105(8.9 \%)$ & $40(3.4 \%)$ & $520(44.1 \%)$ & $47(9.0 \%)$ & $19(3.7 \%)$ \\
\hline Raul Moreira Neto, Brazil ${ }^{17}$ & November, 2014 & 631 & $115(18.2 \%)$ & $19(3.0 \%)$ & $212(33.6 \%)$ & $39(18.2 \%)$ & $6(3.0 \%)$ \\
\hline Suada Tinjić Tuzla B\&H ${ }^{18}$ & May, 2015 & 141 & $38(27.0 \%)$ & $5(3.5 \%)$ & $60(42.6 \%)$ & $16(27.0 \%)$ & $2(3.5 \%)$ \\
\hline Sonal Panchal, India ${ }^{33}$ & October, 2015 & 160 & $3(1.9 \%)$ & 0 & $145(90.6 \%)$ & $3(1.9 \%)$ & 0 \\
\hline Dorota Bomba Opon, Poland ${ }^{18}$ & July, 2017 & 63 & $6(9.5 \%)$ & $3(4.8 \%)$ & $26(41.3 \%)$ & $2(9.5 \%)$ & $1(4.8 \%)$ \\
\hline Gigi Selvan, India* & July, 2018 & 64 & 0 & $1(1.6 \%)$ & 35 (54.7\%) & 0 & $1(1.6 \%)$ \\
\hline Sertac Esin, Turkey ${ }^{18}$ & February, 2019 & 25 & $4(16.0 \%)$ & $1(4.0 \%)$ & $17(68.0 \%)$ & $3(16.0 \%)$ & $1(4.0 \%)$ \\
\hline Edin Medjedovic, B\&H* & July, 2019 & 101 & $10(9.9 \%)$ & $3(3.0)$ & 76 (75.2\%) & $7(9.2 \%)$ & $3(3.9 \%)$ \\
\hline Total & May, 2010-July, 2019 & 3,709 & 379 (10.2\%) & $124(3.3 \%)$ & 1573 (42.4\%) & $153(9.7 \%)$ & $52(3.3 \%)$ \\
\hline
\end{tabular}

${ }^{+}$KANET Kurjak Antenatal Neurodevelopmental Test

*Unpublished data

B\&H Bosnia and Herzegovina

Table 8: The data on $\mathrm{KANET}^{\&}$ scores from low- and high-risk pregnancies shown as normal, borderline and abnormal, comparing abnormal and borderline score prevalence depending on the pregnancy risk

\begin{tabular}{|c|c|c|c|c|c|}
\hline \multirow[b]{2}{*}{ Name of the investigator } & \multirow[b]{2}{*}{ Risk of the pregnancy } & \multicolumn{3}{|c|}{ KANET score } & \multirow[b]{2}{*}{ Total number } \\
\hline & & Normal & Borderline & Abnormal & \\
\hline \multirow[t]{2}{*}{ Lara Spalldi Barisic, $N^{*}=1,344$} & Low & 1,017 & 31 & 0 & 1,048 \\
\hline & High & 177 & 67 & 52 & 296 \\
\hline \multirow[t]{2}{*}{ Panos Antsaklis, $N=1,180$} & Low & 772 & 23 & 0 & 795 \\
\hline & High & 263 & 82 & 40 & 385 \\
\hline \multirow[t]{2}{*}{ Raul Moreira Neto, $N=631$} & Low & 348 & 58 & 0 & 406 \\
\hline & High & 149 & 57 & 19 & 225 \\
\hline \multirow[t]{2}{*}{ Suada Tinjic, $N=141$} & Low & 96 & 33 & 0 & 129 \\
\hline & High & 2 & 5 & 5 & 12 \\
\hline Sonal Panchal, $N=160$ & High & 157 & 3 & 0 & 160 \\
\hline \multirow[t]{2}{*}{ Dorota Bomba Opon, $N=63$} & Low & 30 & 0 & 0 & 30 \\
\hline & High & 24 & 6 & 3 & 33 \\
\hline \multirow[t]{2}{*}{ Gigi Selvan, $N=64$} & Low & 30 & 0 & 0 & 30 \\
\hline & High & 33 & 0 & 1 & 34 \\
\hline Serac Esin, $N=25$ & High & 20 & 4 & 1 & 25 \\
\hline \multirow[t]{2}{*}{ Edin Medjedovic, $N=101$} & Low & 64 & 0 & 0 & 64 \\
\hline & High & 24 & 10 & 3 & 37 \\
\hline Subtotal low-risk & $2,357(94.2 \%)$ & $145(5.8 \%)$ & 0 & $2,502(67.5 \%)$ & \\
\hline Subtotal high-risk & 849 (70.3\%) & $234(19.4 \%)$ & $124(10.3 \%)$ & 1,207 (32.5\%) & \\
\hline Total & $3,206(86.5 \%)$ & $379(10.2 \%)$ & $124(3.3 \%)$ & 3,709 & \\
\hline
\end{tabular}

$\chi^{2}=457.36 ;$ d.f. ${ }^{+}=2 ; p<0.01$

${ }^{\&}$ Kurjak Antenatal Neurodevelopmental Test

${ }^{*} N=$ total number of pregnancies

${ }^{+}$d.f. $=$degrees of freedom 
Out of 1,556 fetuses who were born after KANET testing the distribution based on age is presented in. Most of the children were older than 3 years ( 819 out of 1,556 or $52.6 \%$ ). Most of the infants were developing normally (1,530 or $98.3 \%), 8(0.5 \%)$ had slight and moderate developmental delay, while 18 (1.2\%) had severe developmental delay. The severe and moderate developmental delay could develop more frequently in the group of infants who as fetuses had abnormal KANET scores which are presented in Table 9, which was statistically significant.

Most of the infants with abnormal KANET scores were from high-risk pregnancies, had severe congenital malformations, often intrauterine growth restriction (IUGR), and had more chance to die in utero. To investigate the validity of the KANET test for the prediction of developmental delay and $\mathrm{CP}$, we made predictive value calculations from sensitivity, specificity, and prevalence for all age groups with developmental delay and only for the age group above 2 years for the $\mathrm{CP}$ and severe developmental delay.
The calculations showed that the KANET test has low sensitivity for the detection of $\mathrm{CP}$, and lower sensitivity for the detection of slight, moderate, and severe developmental delay, than for only severe developmental delay. Specificity was rather high for detection of $\mathrm{CP}$, it was lower for the detection of developmental delay. In concordance, the positive predictive value and the falsepositive rate were high. The negative predictive value was high and the false-negative rate was low. If the KANET score is normal, then there is a huge probability of postnatal normal development, with a very small chance that it is false-negative meaning that the probability of abnormal postnatal development is low if KANET was normal. There is a problem with the interpretation of abnormal and borderline KANET scores which appear to have very low sensitivity and positive predictive value and high false-positive rate. This means that based on the borderline or abnormal KANET score one cannot predict the neurodevelopmental outcome, although there is a higher tendency of developmental disorders to occur in

Table 9: Postnatal follow-up of infants who as fetuses had borderline and abnormal KANET\& scores from low-and high-risk pregnancies including termination of pregnancy and postnatal death

\begin{tabular}{|c|c|c|c|c|c|c|}
\hline \multirow[b]{2}{*}{ Name of the investigator $\left(N^{*}\right)$} & \multirow[b]{2}{*}{ KANET score $\left(N^{*}\right)$} & \multicolumn{4}{|c|}{ Postnatal developmental delay $\left(N^{*}\right)$} & \multirow[b]{2}{*}{ Comment } \\
\hline & & No & Slight & Moderate & Severe & \\
\hline \multirow[t]{2}{*}{ Lara Spalldi Barisic, $N=482$} & Borderline $N=36$ & 33 & 0 & 0 & 2 & 1 IUD $^{+}$ \\
\hline & Abnormal $N=19$ & 15 & 0 & 0 & 4 & $\begin{array}{l}\text { All severe congenital malfor- } \\
\text { mations }\end{array}$ \\
\hline \multirow[t]{2}{*}{ Panos Antsaklis, $N=520$} & Borderline $N=47$ & 45 & 0 & 0 & 1 & 1 IUD $^{+}$ \\
\hline & Abnormal $N=19$ & 7 & 0 & 0 & $1^{++}$ & 5 died, 6 terminated \\
\hline \multirow[t]{2}{*}{ Raul Moreira Neto, $N=212$} & Borderline $N=39$ & 39 & 0 & 0 & 0 & - \\
\hline & Abnormal $N=6$ & 3 & 0 & 0 & 3 & $\begin{array}{l}\text { One case of trisomy } 13,18, \\
\text { and } 21\end{array}$ \\
\hline \multirow[t]{2}{*}{ Suada Tinjic, $N=60$} & Borderline $N=16$ & 16 & 0 & 0 & 0 & - \\
\hline & Abnormal $N=2$ & 1 & 1 & 0 & 0 & $\begin{array}{l}\text { IUGR** one with slight devel- } \\
\text { opmental delay }\end{array}$ \\
\hline \multirow[t]{2}{*}{ Sonal Panchal, $N=145$} & Borderline $N=3$ & 0 & 0 & 2 & 1 & - \\
\hline & Abnormal $N=0$ & 0 & 0 & 0 & 0 & - \\
\hline \multirow[t]{2}{*}{ Dorota Bomba Opon, $N=26$} & Borderline $N=2$ & 2 & 0 & 0 & 0 & - \\
\hline & Abnormal $N=1$ & 0 & 0 & 0 & 1 & $\begin{array}{l}\text { One with severe delay } \\
\text { Kagami Ogata syndrome }\end{array}$ \\
\hline \multirow[t]{2}{*}{ Gigi Selvan, $N=35$} & Borderline $N=0$ & 0 & 0 & 0 & 0 & - \\
\hline & Abnormal $N=1$ & 0 & 0 & 1 & 0 & IUGR** \\
\hline \multirow[t]{2}{*}{ Serac Esin, $N=17$} & Borderline $N=3$ & 3 & 0 & 0 & 0 & - \\
\hline & Abnormal $N=1$ & 0 & 0 & 0 & 1 & $\begin{array}{l}\text { Trisomy } 18 \text {, died in the first } \\
\text { day of life }\end{array}$ \\
\hline \multirow[t]{2}{*}{ Edin Medjedovic, $N=76$} & Borderline $N=7$ & 7 & 0 & 0 & 0 & - \\
\hline & Abnormal $N=3$ & 3 & 0 & 0 & 3 & $\begin{array}{l}2 \text { severe congenital malfor- } \\
\text { mations and one IUGR** }\end{array}$ \\
\hline Subtotal normal KANET & $1,351(86.8 \%)$ & $1,348(99.8)$ & 0 & $2(0.1 \%)$ & $1(0.1 \%)$ & $\begin{array}{l}\text { One with severe delay } \\
\text { Kagami Ogata syndrome }\end{array}$ \\
\hline Subtotal borderline, KANET & $153(9.8 \%)$ & $145(94.8 \%)$ & 0 & $2(1.3 \%)$ & $4(2.6 \%)$ & 2 IUD (1.3\%) \\
\hline Subtotal abnormal, KANET & $52(3.3 \%)$ & $26(50.0 \%)$ & $1(1.9 \%)$ & $1(1.9 \%)$ & $13(25.0 \%)$ & 11 terminated or died (21.2\%) \\
\hline Total & $1,556(100.0 \%)$ & $1,519(97.6 \%)$ & $1(0.1 \%)$ & $5(0.3 \%)$ & $18(1.2 \%)$ & $13(0.8 \%)$ \\
\hline
\end{tabular}

$\chi^{2}=315.28 ;$ d.f. ${ }^{++}=6 ; p<0.01$

\&Kurjak Antenatal Neurodevelopmental Test

${ }^{*} N$ number of infants

${ }^{+}$IUD intrauterine death

${ }^{++}$One infant with CP (with the previous case of cerebral palsy in the family)

**IUGR intrauterine growth restriction

${ }^{+++}$d.f. $=$degrees of freedom 
infants with abnormal KANET scores from high-risk pregnancies, however, it cannot be concluded concerning the type and severity of the disorder, especially not CP. As it has been pointed out many times in the papers published up to now by our team, the most important aim of KANET introduction was too early predict the development of $\mathrm{CP}$ to intervene early enough to decrease possible consequences of the condition on individual, family, societal, and public health level. We were aware that early diagnosis of CP was and is not easy even postnatally. There is a rule saying that making the diagnosis of $\mathrm{CP}$ is inversely proportional to age, undermining confidence in diagnosing CP early. Possible barriers in postnatal early diagnosis could be: ${ }^{132}$

- There are no clinical signs on the clinical examination that can confirm or rule out the diagnosis.

- High probability of false-positive diagnosis.

- Lack of specific biomarkers, genetic or other tests helpful in making the diagnosis.

- Due to grief and the stigma of the family with the child diagnosed with $\mathrm{CP}$, there is the desire of the healthcare providers to rule out every treatable condition first by wide differential diagnosis.

- There are no curative treatments and evidence of the efficacy of the early intervention is scarce.

Another important recurrent discussion lasting for decades on $\mathrm{CP}$ is when the earliest diagnosis of CP could be made to avoid the development of deformities connected with the disease. ${ }^{132}$ For many years from the 1970s, it is accepted that it is almost impossible to make the diagnosis of CP in infancy, and that the acceptable age for the diagnosis is between 3 years and 5 years. ${ }^{132}$ It has been claimed that in a well-developed healthcare system the diagnosis of CP could be made in one of five children at the age of 6 months and in more than half of the cases after the first year of life. ${ }^{132}$ There is a belief that CP is neurologically silent in the first few months of age and almost impossible to be diagnosed, which was the reason for the development of the concept of GMs by Prechtl et al. which enabled detection of neurological impairment by the recording of GMs by a camera and assessing them off-line. The assessment was time-consuming and not practical or clinically applicable for everyday clinical practice. However, in the recently published guidelines for the early diagnosis (by the age of five months in highrisk infants) of CP the following criteria have been mentioned: ${ }^{133}$

- General movement assessment [sensitivity $98 \%(95 \% \mathrm{Cl}$ 74-100\%); specificity 91\% (95\% Cl 83-93\%)] at fidgety age (26).

- Magnetic resonance imaging at term equivalent age (sensitivity 86-100\%, specificity $89-97 \%$ ).

- Hammersmith Infant Neurological Examination (HINE) (sensitivity at 3 months $96 \%$, specificity $85 \%, \mathrm{Cl}$ not reported). ${ }^{134}$

Mentioned criteria are aimed at high-risk infants, while infants with CP who do not have newborn detectable risks, and are seemingly healthy at birth, are less likely to be followed-up, and there is a need for identifying these infants and administering best-practice tools in order not to miss the diagnosis of $C P$, which is nowadays in low-risk population very often overlooked and missed. ${ }^{132}$ For such term and high-risk preterm infants automated computer-assisted/smartphone GMs assessment tool is under development, ${ }^{135}$ which will make a time-consuming assessment of GMs more practical, standardized, and clinically applicable.

We are aware of the weaknesses of our study: nine investigators included, high dropout rate, heterogeneity of the investigation group in terms of nationality and race, inhomogeneous groups of pregnant women in terms of risk of pregnancy, social status, age, parity, and many other characteristics. Although KANET was standardized and was advised to be used in everyday clinical practice, it would be much better if all those weaknesses could have been avoided. ${ }^{85,126}$

The main weakness of the investigation is the postnatal follow-up of infants, which was dependent on local circumstances, and the information for infants who had developmental delays has been obtained from the parents and available medical charts. Such an approach may cause that some children with developmental delay may have been missed, without awareness of the investigator(s). That is why the results of the study should be taken with due caution.

Based on the results of the study, we can conclude that if the KANET score is normal then there is a high probability that the development of the infant will be normal, with a very low probability that the child with developmental delay would have been missed. However, if the KANET score is borderline and especially if abnormal in high-risk pregnancy, the postnatal development of the child may appear abnormal. Due to a high false-positive rate in those fetuses, thorough postnatal prospective neurodevelopmental follow-up especially in high-risk infants with a positive family history of $\mathrm{CP}$ should be advised. ${ }^{132}$ To make an early diagnosis of CP in high-risk cases, the protocol proposed by Novak et al. should be followed, ${ }^{132}$ while for low-risk infants with abnormal KANET scores the protocol should be individualized and follow-up established on a case by case basis. The future development of fetal neurology should be multidisciplinary with special emphasis on a scrutinized postnatal follow-up of infants who had abnormal and borderline KANET scores and were born from high-risk pregnancies.

\section{OrCID}

Asim Kurjak (1) https://orcid.org/0000-0002-1680-3030

Milan Stanojević (1) https://orcid.org/0000-0002-3124-5575

Panos Antsaklis (1) https://orcid.org/0000-0003-2106-5922

\section{References}

1. Salihagic-Kadic A, Kurjak A, Medic M, et al. New data about embryonic and fetal neurodevelopment and behaviour obtained by 3D and 4D sonography. J Perinat Med 2005;33:478-490.

2. Pomeroy SL, Voipe JJ. Development of the nervous system. In: Polin RA, FoxWW, ed. Fetal and neonatal physiology. Philadelphia-LondonToronto-Montreal-Sydney-Tokyo: WB Saunders Copmany; 1992. 1491-1509.

3. O'Rahilly R, Muller F. Minireview:summary of the initial development of the human central nervous system. Teratology 1999;60(1):39-41. DOI: 10.1002/(SICI)1096-9926(199907)60:1<39::AID-TERA11>3.0.CO;2-I.

4. Kostović I, Judaš M, Petanjek Z, et al. Ontogenesis of goal-directed behavior: anatomo-functional considerations. Int J Psychophysiol 1995;19(2):85-102. DOI: 10.1016/0167-8760(94)00081-O.

5. Schaher S. Determination and differentiation in the development of the nervous system. In: Kandel ER, Schwartz JH, ed. Principles of Neural Science. 2nd ed., New York: Elsevier Science Publishing; 1985. pp. 730-732.

6. Kostovic I. Prenatal development of nucleus basalis complex and related fibre system in man: a histochemical study. Neuroscience 1986;17(4):1047-1077. DOI: 10.1016/0306-4522(86)90077-1.

7. Okado N. Onset of synapse formation in the human spinal cord. J Comp Neurol 1981;10(201):211-219. DOI: 10.1002/cne.902010206.

8. Kostovic I. Zentralnervensystem. In: Hinrichsen KV, ed. Humanembryologie. Berlin: Springer-Verlag; 1990. 381-448. 
9. Prechtl FHR. Ultrasound studies of human fetal behaviour. Early Hum Dev 1985;2(2):91-98. DOI: 10.1016/0378-3782(85)90173-2.

10. lanniruberto A, Tajani E. Ultrasonographic study of fetal movements. Semin Perinatal 1981;4:175-181.

11. Goto S, Kato TK. Early movements are useful for estimating the gestational weeks in the first trimester of pregnancy. In: Levski RA, Morley P, ed. Ultrasound '82. Oxford: Pergamon Press; 1983. pp. 577-582.

12. Joseph R. Fetal brain and cognitive development. Dev Rev 1999;20(1):81-98. DOI: 10.1006/drev.1999.0486.

13. de Vries JIP, Visser GHA, Prechtl HFR. The emergence of fetal behavior I. Qualitative aspects. Early Hum Dev 1982;7(4):301-322. DOI: 10.1016/0378-3782(82)90033-0.

14. Kostovic I, Rakic P. Development of prestriate visual projections in the monkey and human fetal cerebrum revealed by transient cholinesterase staining. J Neurosci 1984;4(1):25-42. DOI: 10.1523/ JNEUROSCI.04-01-00025.1984.

15. D'Elia A, Pighetti M, Moccia G, et al. Spontaneous motor activity in the normal fetus. Early Human Dev 2001;65(2):139-144. DOI: 10.1016/ S0378-3782(01)00224-9.

16. Prechtl HFR, Einspieler C. Is neurological assessment of the fetus possible? Eur J Obstet Gynecol Reprod Biol 1997;75(1):81-84. DOI: 10.1016/S0301-2115(97)00197-8.

17. Roodenburg PJ, Wladimiroff JW, van Es A, et al. Classification and quantitative aspects of fetal movements during the second half of pregnancy. Early Hum Dev 1991;25(1):19-35. DOI: 10.1016/03783782(91)90203-F.

18. Prechtl FHR. Qualitative changes of spontaneous movements in fetus and preterm infant are a marker of neurological dysfunction. Early Hum Dev 1990;23(3):151-158. DOI: 10.1016/0378-3782(90)90011-7.

19. Kurjak A, Azumendi G, Veček N, et al. Fetal hand movements and facial expression in normal pregnancy studied by four-dimensional sonography. J Perinat Med 2003;31(6):496-508. DOI: 10.1515/ JPM.2003.076.

20. Andonotopo W, Stanojevic M, Kurjak A, et al. Assessment of fetal behavior and general movements by four-dimensional sonography. Ultrasound Rev Obstet Gynecol 2004;4(2):103-114. DOI: 10.3109/14722240400016895.

21. Kurjak A, Stanojevic M, Azumendi G, et al. The potential of fourdimensional (4D) ultrasonography in the assessment of fetal awareness. J Perinat Med 2005;33(1):4653. DOI: 10.1515/JPM.2005.008.

22. Kurjak A, Pooh RK, Merce LT, et al. Structural and functional early human development assessed by three-dimensional (3D) and fourdimensional (4D) sonography. Fertil Steril 2005;84(5):1285-1299. DOI: 10.1016/j.fertnstert.2005.03.084.

23. Kurjak A, Miskovic $B$, Andonotopo W, et al. How useful is $3 D$ and $4 D$ ultrasound in perinatal medicine. J Perinat Med 2007;35(1):10-27. DOI: 10.1515/JPM.2007.002.

24. Andonotopo W, Medic M, Salihagic-Kadic A, et al. The assessment of embryonic and fetal neurodevelopment in early pregnancy: comparison between $2 \mathrm{D}$ and $4 \mathrm{D}$ sonographic scanning. J Perinat Med 2005;33:406-414.

25. Kurjak A, Stanojevic M, Andonotopo W, et al. Fetal behavior assessed in all three trimesters of normal pregnancy by four-dimensional ultrasonography. Croat Med J 2005;46:772-780.

26. Pooh RK, Ogura T. Normal and abnormal fetal hand positioning and movement in early pregnancy detected by three- and fourdimensional ultrasound. Ultrasound Rev Obset Gynecol 2004;4:4651.

27. Kurjak A, Stanojevic M, Andonotopo W, et al. Behavioral pattern continuity from prenatal to postnatal life-a study by four-dimensional (4D) ultrasonography. J Perinat Med 2004;32(4):346-353. DOI: 10.1515/ JPM.2004.065.

28. Andonotopo W, Kurjak A, Kosuta MI. Behavior of anencephalic fetus studied by 4D sonography. J Matern Fetal Neonatal Med 2005;17(2):165-168. DOI: 10.1080/jmf.17.2.165.168.

29. Andonopo W, Kurjak A. The assessment of fetal behavior of growth restricted fetuses by 4D sonography. J Perinat Med 2006;34:471-478.
30. Kurjak A, Andonotopo W, Hafner T, et al. Normal standards for fetal neurobehavioural developments -longitudinal quantification by four-dimensional sonography. J Perinat Med 2006;34:56-65.

31. Kurjak A, Azumendi G, Andonotopo W, et al. Three- and fourdimensional ultrasonography for the structural and functional evaluation of the fetal face. Am J Obstet Gynecol 2007;196(1):16-28. DOI: 10.1016/j.ajog.2006.06.090.

32. Walusinski O, Kurjak A, Andonotopo W, et al. Fetal yawning assessed by 3D and 4D sonography. Ultrasound Rev Obstet Gynecol 2005;5(3):210-217. DOI: 10.3109/14722240500284070.

33. Rosenbaum P, Paneth N, Leviton A, et al. A report: the definition and classification of cerebral palsy April 2006. Dev Med Child Neurol 2007;109(suppl):8-14.

34. Palmer FB. Strategies for the early diagnosis of cerebral palsy. J Pediatr 2004;145(2):S8-S11. DOI: 10.1016/j.jpeds.2004.05.016.

35. Walstab JE, Bell RJ, Reddihough DS, et al. Factors identified during the neonatal period associated with risk of cerebral palsy. Australian and New Zeland Journal of Obstetrics and Gynecology 2004;44(4):342346. DOI: 10.1111/j.1479-828X.2004.00249.x.

36. Nelson KB, Ellenberg JH. Neonatal signs as predictors of cerebral palsy. Pediatrics 1979;64:225-232.

37. Amiel Tison C, Gosselin J, Kurjak A. Neurosonography in the seconf half of fetal life: a neonatologist point of view. J Perinat Med 2006;34:437-446.

38. Gosselin J, Gahagan S, Amiel-Tison C. The Amiel-Tison neurological assessment at term: conceptual and methodological continuity in the course of follow-up. Ment Retard Dev Disabil Res Rev 2005;11(1):34-51. DOI: 10.1002/mrdd.20049.

39. Amiel-Tison C. Update of the Amiel-Tison neurological assessment for the term neonate or at 40 weeks corrected age. Pediatr Neurol 2002;27(3):196-212. DOI: 10.1016/S0887-8994(02)00436-8

40. Volpe JJ. Neurological examination: Normaland abnormal fetures. In: Neurology of the newborn. 4th ed., Philadelphia: WB Saunders; 2001. p 127.

41. Einspieler C, Prechtl HFR, Bos AF, et al. Prechtl's, ethod on the qualitative assessment of general movements in preterm, term and young infants. Mac Keith Press, Cambridge; 2004. pp. 67-71

42. Hadders-Algra M. General movements: a window for early identification of children at high risk for developmental disorders. J Pediatr 2004;145(2):S12-S18. DOI: 10.1016/j.jpeds.2004.05.017.

43. Hadders-Algra M, Nieuwendijk AWK, Maitijn A, et al. Assessment of general movements: towards a better understanding of a sensitive method to evaluate brain function in young infants. Dev Med Child Neurol 1997;39(2):89-99. DOI: 10.1111/j.1469-8749.1997.tb07390.x.

44. Bekedam DJ, Visser GHA, de Vries JJ, et al. Motor behaviour in the growth retarded fetus. Early Hum Dev 1985;12(2):155-165. DOI: 10.1016/0378-3782(85)90178-1.

45. Cioni G, Prechtl HF. Preterm and early postterm motor behaviour in low-risk premature infants. Early Hum Dev 1990;23(3):159-191. DOI: 10.1016/0378-3782(90)90012-8.

46. Seme-Ciglenečki P. Predictive value of assessment of general movements for neurological development of high-risk preterm infants: comparative study. Croat Med J 2003;44:721-727.

47. Cioni G, Prechtl HFR, Ferrari F, et al. Which better predicts later outcome in full term infants: quality of general movements or neurological examination? Early Hum Dev 1997;50(1):71-85. DOI: 10.1016/S0378-3782(97)00094-7.

48. Einspieler C, Prechtl HFR, Ferrari F, et al. The qualitative assessment of general movements in preterm, term and young infants-review of the methodology. Early Hum Dev 1997;24(1):47-60. DOI: 10.1016/ S0378-3782(97)00092-3.

49. Ferrari F, Cioni G, Einspieler C, et al. Cramped synchronized general movements in preterm infants as an early marker for cerebral palsy. Arch Pediatr Adolesc Med 2002;156(5):460-467. DOI: 10.1001/ archpedi.156.5.460.

50. Prechtl HFR. State of the art of a new functional assessment of the young nervous system. An early predictor of cerebral palsy. Early Hum Dev 1997;50(1):1-11. DOI: 10.1016/S0378-3782(97)00088-1. 
51. Kurjak A, Jackson D, ed. An atlas of three- and four-dimensional sonography in obstetrics and gynecology. London: Taylor \& Francis Group; 2004.

52. Sarnat HB. Anatomic and physiologic correlates of neurologic development in prematurity. In: Sarnat HB, ed. Topics in neonatal neurology. New York: Grune and Stratton; 1984. pp. 1-24.

53. Sarnat HB. Functions of the corticospinal and corticobulbar tracts in the human newborns. J Pediatr Neurol 2003;1(01):3-8. DOI: 10.1055/s0035-1557162.

54. Amiel-Tison C. Clinical assessment of the infant nervous system. In: Levente MI, Chervenak FA, Whittle M, ed. Fetal and neonatal neurology and neurosurgery. 3rd ed., London: Churchill Livingstone; 2001. pp. 99-120.

55. Salisbury AL, Duncan Fallone M, Lester B. Neurobehavioral assessment from fetus to infant: the NICU network neurobehavioral scale and the fetal neurobehavioral coding system. MRDD Research Reviews 2005;11(1):14-20. DOI: 10.1002/mrdd.20058.

56. de Vries JIP, Visser GHA, Prechtl HFR. Fetal motility in the first half of pregnancy. In: Prechtl HFR, ed. Continuity of neural functions from prenatal to postnatal life. Clin Dev Med 94 Oxford: Blackwell; 1984. pp. 46-63.

57. Kostović l, Seress L, Mrzljak L, et al. Early onset of synapse formation in the human hippocampus: a correlation with Nissl-Golgi architectonics in 15- and 16.5-week-old fetuses. Neuroscience 1989;30(1):105-116. DOI: 10.1016/0306-4522(89)90357-6.

58. Mutch L, Alberman E, Hagberg B, et al. Cerebral palsy epidemiology: where are we now and where are we going? Dev Med Child Neurol 1992;34(6):547-551. DOI: 10.1111/j.1469-8749.1992.tb11479.x.

59. Bax M, Goldstein M, Rosenbaum P, et al. Executive committee for the definition of cerebral palsy. Proposed definition and classification of cerebral palsy, April 2005. Dev Med Child Neurol 2005;47(8):571-576. DOI: $10.1017 /$ S001216220500112X.

60. Sankar C, Mundkur N. Cerebral palsy-definition, classification, etiology and early diagnosis. Indian J Pediatr 2005;72(10):865-868. DOI: 10.1007/BF02731117.

61. Shapiro BK. Cerebral palsy: a reconceptualization of the spectrum. J Pediatr 2004;145(Suppl. 2):S3-S7. DOI: 10.1016/j.jpeds.2004.05.014.

62. Amiel-Tison C, GosselinJ, Infante-Rivard C. Head growth and cranial assessment at neurological examination in infancy. Dev Med Child Neurol 2002;44(9):643-648. DOI: 10.1111/j.1469-8749.2002.tb00850.x.

63. Pooh RK, Pooh K, Nakagawa Y, et al. Clinical application of threedimensional ultrasound in fetal brain assessment. Croat Med J 2000;41:245-251.

64. Campbell S, Lees C, Moscoso G, et al. Ultrasound antenatal diagnosis of cleft palate by a new technique: the 3D "reverse face" view. Ultrasound Obstet Gynecol 2005;25(1):12-18. DOI: 10.1002/uog. 1819.

65. Kurjak A, Miskovic B, Stanojevic M, et al. New scoring system for fetal neurobehavior assessed by three- and four-dimensional sonography. J Perinat Med 2008;36(1):73-81. DOI: 10.1515/JPM.2008. 007.

66. DiPietro JA. Neurobehavioral assessment before birth. Ment Retard Dev Disabil Res Rev 2005;11(1):4-13. DOI: 10.1002/mrdd.20047.

67. Yigiter AB, Kavak ZN. Normal standards of fetal behavior assessed by four-dimensional sonography. J Matern Fetal Neonatal Med 2006;19(11):707-721. DOI: 10.1080/14767050600924129.

68. Rees S, Harding R. Brain development during fetal life: influences of the intra-uterine environment. Neurosci Lett 2004;361(1-3):111-114. DOI: 10.1016/j.neulet.2004.02.002.

69. Kurjak A, Carrera J, Stanojevic M, et al. The role of 4D sonography in the neurological assessment of early human development. Ultrasound Rev Obstet Gynecol 2004;4(3):148-159. DOI: 10.3109/14722240400017075.

70. Eidelman Al. The living fetus e dilemmas in treatment at the edge of viability. In: Blazer S, Zimmer EZ, ed. The embryo: scientific discovery and medical ethics. . Basel: Karger; 2005. pp. 351-370.

71. Haak P, Lenski M, Hidecker MJC, et al. Cerebral palsy and aging. Dev Med Child Neurol 2009;51(Suppl 4):16-23. DOI: 10.1111/j.14698749.2009.03428.x.
72. Einspieler C, Prechtl HF. Prechtl's assessment of general movements: a diagnostic tool for the functional assessment of the young nervous system. Ment Retard Dev Disabil Res Rev 2005;11(1):61-67. DOI: 10.1002/mrdd.20051.

73. Moster D, Wilcox AJ, Vollset SE, et al. Cerebral palsy among term and postterm births. JAMA 2010;304(9):976-982. DOI: 10.1001/ jama.2010.1271.

74. Stanojevic M, Kurjak A, Salihagić-Kadić A, et al. Neurobehavioral continuity from fetus to neonate. J Perinat Med 2011;39(2):171-177. DOI: 10.1515/jpm.2011.004.

75. Stanojevic M, Zaputovic S, Bosnjak AP. Continuity between fetal and neonatal neurobehavior. Semin Fetal Neonatal Med 2012;17(6):324329. DOI: 10.1016/j.siny.2012.06.006.

76. DiPietro JA, Costigan KA, Pressman EK. Fetal state concordance predicts infant state regulation. Early Hum Dev 2002;68(1):1-13. DOI: 10.1016/S0378-3782(02)00006-3.

77. Thoman E, Denenberg V, Sievel J, et al. State organization in neonate: developmental inconsistency indicates risk for developmental dysfunction. Neuropediatrics 1981;12(01):45-54. DOI: 10.1055/s-20081059638.

78. St James-Roberts I, Menon-Johansson P. Predicting infant crying from fetal movement data: an exploratory study. Early Hum Dev 1999;54(1):55-62. DOI: 10.1016/S0378-3782(98)00084-X.

79. de Vries Jl, Visser GH, Prechtl HF. The emergence of fetal behaviour. II. Quantitative aspects Early Hum Dev 1985;12(2):99-120. DOI: 10.1016/0378-3782(85)90174-4.

80. de Vries Jl, Visser GH, Prechtl HF. The emergence of fetal behaviour. III. Individual differences and consistencies. Early Hum Dev 1988;16(1):85-103.

81. Kurjak A, Luetic AT. Fetal neurobehavior assessed by threedimensional/four dimentional sonography. Zdrav Vestn 2010;79:790799.

82. Merz E, Abramowicz JS. 3D/4D Ultrasound in prenatal diagnosis: is it time for routine use? Clin Obstet Gynecol 2012;55(1):336-351. DOI: 10.1097/GRF.0b013e3182446ef7.

83. Kurjak A, Vecek N, Hafner T, et al. Prenatal diagnosis: what does fourdimensional ultrasound add? J Perinat Med 2002;30(1):57-62. DOI: 10.1515/JPM.2002.008

84. Kurjak A, Vecek N, Kupesic S, et al. Four dimensional ultrasound: how muvh does it improve perinatal practice? In: Carrera JM, Chervenak FA, Kurjak $A$, ed. Controversies in perinatal medicine, studies on the fetus as a patient. New York: A CRC Press Company Parthenon Publishing; 2003. p. 222.

85. Predojevic M, Miskovic B, Ahmed B, et al. An attempt to standardize Kurjak's antenatal neurodevelopmental test: osaka consensus statement. Donald School J Ultrasound Obstet Gynecol 2011;5(4):317329. DOI: 10.5005/jp-journals-10009-1209.

86. Kurjak A, Pooh R, Tikvica A, et al. Assessment of fetal neurobehaviour by 3D/4D ultrasound. Fetal Neurology 2009. pp. 222-250.

87. Kurjak A, Tikvica A, Stanojevic M, et al. The assessment of fetal neurobehavior by three-dimensional and four-dimensional ultrasound. J Matern Fetal Neonatal Med 2008;21(10):675-684. DOI: 10.1080/14767050802212166.

88. Tomasovic S, Predojevic M. 4D Ultrasound - Medical devices for recent advances on the etiology of cerebral palsy. Acta Inform Med 2011;19(4):228-234. DOI: 10.5455/aim.2011.19.228-234.

89. Pooh K, Pooh RK. Fetal ventriculomegaly. Donald School J Ultrasound Obstet Gynecol 2007;1(4):40-46. DOI: 10.5005/jp-journals-10009-1118.

90. Miskovic B, Ahmed B, Younis $M$, et al. An attempt to introduce neurological test for fetus based on 3D and 4D sonography. Donald School J Ultrasound Obstet Gynecol 2008;2(4):29-44. DOI: 10.5005/ jp-journals-10009-1076.

91. Nijhuis JG, ed. Fetal behaviour: developmental and perinatal aspects. Oxford: Oxford University Press; 1992.

92. Kuno A, Akiyama M, Yamashiro C, et al. Three-dimensional sonographic assessment of fetal behavior in the early second trimester of pregnancy. J Ultrasound Med 2001;20(12):1271-1275. DOI: 10.7863/jum.2001.20.12.1271. 
93. Koyanagi T, Horimoto $\mathrm{N}$, Maeda $\mathrm{H}$, et al. Abnormal behavioral patterns in the human fetus at term: correlation with lesion sites in the central nervous system after birth. J Child Neurol 1993;8(1):19-26. DOI: $10.1177 / 088307389300800103$.

94. Stanojevic M, Kurjak A. Continuity between fetal and neonatal neurobehavior. Donald School J Ultrasound Obstet Gynecol 2008;2(3):64-75. DOI: 10.5005/jp-journals-10009-1066.

95. Kurjak A, Abo-Yaqoub S, Stanojevic M, et al. The potential of 4D sonography in the assessment of fetal neurobehavior--multicentric study in high-risk pregnancies. J Perinat Med 2010;38(1):77-82. DOI: 10.1515/jpm.2010.012.

96. Abo-Yaqoub $S$, Kurjak $A$, Mohammed $A B$, et al. The role of 4-D ultrasonography in prenatal assessment of fetal neurobehaviour and prediction of neurological outcome. J Matern Fetal Neonatal Med 2012;25(3):231-236. DOI: 10.3109/14767058.2011.568552.

97. Talic A, Kurjak A, Ahmed B, et al. The potential of $4 D$ sonography in the assessment of fetal behavior in high-risk pregnancies. J Matern Fetal Neonatal Med 2011;24(7):948-954. DOI: 10.3109/14767058.2010.534830.

98. Miskovic B, Vasilj O, Stanojevic M, et al. The comparison of fetal behavior in high risk and normal pregnancies assessed by four dimensional ultrasound. J Matern Fetal Neonatal Med 2010;23(12):1461-1467. DOI: 10.3109/14767051003678200.

99. Talic A, Kurjak A, Stanojevic M, et al. The assessment of fetal brain function in fetuses with ventrikulomegaly: the role of the KANET test. J Matern Fetal Neonatal Med 2012;25(8):1267-1272. DOI: 10.3109/14767058.2011.634463.

100. Horimoto $\mathrm{N}$, Koyanagi $\mathrm{T}$, Maeda $\mathrm{H}$, et al. Can brain impairment be detected by in utero behavioural patterns? Arch Dis Child 1993;69(1 Spec No):3-8. DOI: 10.1136/adc.69.1_Spec_No.3.

101. Morokuma S, Fukushima K, Yumoto Y, et al. Simplified ultrasound screening for fetal brain function based on behavioral pattern. Early Hum Dev 2007;83(3):177-181. DOI: 10.1016/j.earlhumdev.2006.05.012.

102. Nijhuis JG, Prechtl HFR, Martin CB, et al. Are tere behavioral states in the human fetus? Early Hum Dev 1982;6(2):177-195. DOI: 10.1016/0378-3782(82)90106-2.

103. Almli CR, Ball RH, Wheeler ME. Human fetal and neonatal movement patterns: gender difference and fetal-to-neonatal continuity. Dev Psychobiol 2001;38(4):252-273. DOI: 10.1002/dev.1019.

104. DiPietro JA, Bornstein MH, Costigan KA, et al. What does fetal movement predict about behavior during the first two years of life? Dev Phych 2002;40(4):358-371. DOI: 10.1002/dev.10025.

105. DiPietro JA, Hodgson DM, Costigan KA, et al. Fetal antecedents of infant temperament. Child Dev 1996;67(5):2568-2583. DOI: 10.2307/1131641.

106. Salihagić-Kadić A, Medić M, Kurjak A, et al. Four-dimensional sonography in the assessment of fetal functional neurodevelopment and behavioural paterns. Ultrasound Rev Obstet Gynecol 2005;5(2):154-168. DOI: 10.3109/14722240500190640.

107. Kurjak A, Carrera J, Medic M, et al. The antenatal development of fetal behavioral patterns assessed by four-dimensional sonography. J Matern Fetal Neonatal Med 2005;17(6):401-416. DOI: 10.1080/14767050400029657.

108. Honemeyer U, Kurjak A, The use of KANET test to assess fetal CNS function. First 100 cases. 10th World Congress of Perinatal Medicine 8-11 November 2011. Uruguay. Poster presentation P209.

109. Lebit DF, Vladareanu PD. The role of $4 D$ ultrasound in the assessment of fetal behaviour. Maedica (Buchar) 2011;6(2):120-127.

110. Vladareanu R, Lebit $D$, Constantinescu $S$. Ultrasound assessment of fetal neurobehaviour in high-risk pregnancies. Donald School J Ultrasound Obstet Gynecol 2012;6(2):Q132-Q147. DOI: 10.5005/ jp-journals-10009-1235.

111. Honemeyer $\mathrm{U}$, Talic A, Therwat A, et al. The clinical value of KANET in studying fetal neurobehavior in normal and at-risk pregnancies. J Perinat Med 2012;0(0):1-11.

112. Hepper PG. Fetal behavior: why so skeptical? Ultrasound Obstet Gynecol 1996;8(3):145-148.DOI: 10.1046/j.1469-0705.1996.08030145.x.
113. Greenwood C, Newman S, Impey L, et al. Cerebral palsy and clinical negligence litigation: a cohort study. BJOG 2003;110(1):6-11. DOI: 10.1046/j.1471-0528.2003.02095.x.

114. Strijbis EMM, Oudman I, van Essen P, et al. Cerebral palsy and the application of the international criteria for acute intrapartum hypoxia. Obstet Gynecol 2006;107(6):1357-1365. DOI: 10.1097/01. AOG.0000220544.21316.80.

115. de Vries JI, Fong BF. Changes in fetal motility as a result of congenital disorders: an overview. Ultrasound Obstet Gynecol 2007;29(5):590599. DOI: 10.1002/uog.3917.

116. de Vries Jl, Fong BF. Normal fetal motility: an overview. Ultrasound Obstet Gynecol 2006;27(6):701-711. DOI: 10.1002/uog.2740.

117. Rosier-van Dunné FM, van Wezel-Meijler G, Bakker MP, et al. General movements in the perinatal period and its relation to echogenicity changes in the brain. Early Hum Dev 2010;86(2):83-86. DOI: 10.1016/j. earlhumdev.2010.01.023.

118. Hata T, Kanenishi K, Akiyama M, et al. Real-time 3-D sonographic observation of fetal facial expression. J Obstet Gynaecol Res 2005;31(4):337-340. DOI: 10.1111/j.1447-0756.2005.00298.x.

119. Kozuma S, Baba K, Okai T, et al. Dynamic observation of the fetal face by three-dimensional ultrasound. Ultrasound Obstet Gynecol 1999;13(4):283-284.

120. Kurjak A, Talic A, Honemeyer U, et al. Comparison between antenatal neurodevelopmental test and fetal Doppler in the assessment of fetal well being. J Perinat Med 2013;41(1):107-114. DOI: 10.1515/jpm-20120018.

121. Athanasiadis AP, Mikos T, Tambakoudis GP, et al. Neurodevelopmental fetal assessment using KANET scoring system in low and high risk pregnancies. J Matern Fetal Neonatal Med 2013;26(4):363-368. DOI: 10.3109/14767058.2012.695824.

122. Neto RM. KANET in Brazil: first experience. Donald School J Ultrasound ObstetGynecol 2015;9(1):1-5. DOI: 10.5005/jp-journals-100091384.

123. Hanaoka U, Hata T, Kanenishi K, et al. Does ethnicity have an effect on fetal behavior? a comparison of Asian and Caucasian populations. J Perinatal Med 2016;44(2):217-221. DOI: 10.1515/jpm2015-0036.

124. Antsaklis $P$, Porovic $S$, Daskalakis $G$, et al. $4 D$ assessment of fetal brain function in diabetic patients. J Perinat Med 2017;45(6):711-715. DOI: 10.1515/jpm-2016-0394.

125. Kurjak A, Predojevic M, Salihagic-Kadic A. Fetal brain function: lessons learned and future challenges of 4D sonography. Donald School J Ultrasound Obstet Gynecol 2010 2011;2(5):85-92.

126. Predojevic $M$, Vladareanu $R$, Antsaklis $P$, et al. Is Kurjak antenatal neurodevelopmental test ready for routine clinical application: Bucharest consensus statement. Donald School J Ultrasound Obstet Gynecol 2015;9(3):260-265. DOI: 10.5005/jp.journals-1000091412.

127. Predojević M, Talić A, Stanojević M, et al. Assessment of motoric and hemodynamic parameters in growth restricted fetuses - case study. J Matern Fetal Neonatal Med 2014;27(3):247-251. DOI: 10.3109/14767058.2013.807241.

128. Spencer-Smith MM, Spittle AJ, Doyle LW, et al. Long-term benefits of homebased preventive care for preterm infants: a randomized trial. Pediatr 2012;130(6):1094-1101. DOI: 10.1542/peds.20120426.

129. Hata T, Hanaoka U, Mostafa AboEllail MA, et al. Is there a sex difference in fetal behavior? a comparison of the KANET test between male and female fetuses. J Perinat Med 2016;44(5):585-588. DOI: 10.1515/jpm2015-0387.

130. Kurjak A, Antsaklis P, Stanojevic M, et al. Multicentric studies of the fetal neurobehavior by KANET test. J Perinat Med 2017;45(6):717-727. DOI: 10.1515/jpm-2016-0409.

131. Kurjak A, Stanojevic M, Spalldi Barisic L, et. al. A critical appraisal of Kurjak antenatal neurodevelopmental test (KANET) - five years of wide clinical use. Donald School J Ultrasound Obstet Gynecol 2020. (in press). 
132. Velde A, Morgan C, Novak I, et al. Early diagnosis and classification of cerebral palsy: an historical perspective and barriers to an early diagnosis. J Clin Med 2019;8(10):1599. DOI: 10.3390/jcm8101599.

133. Novak I, Morgan C, Adde L, et al. Early, accurate diagnosis and early intervention in cerebral palsy: advances in diagnosis and treatment. JAMA Pediatr 2017;171(9):897-900. DOI: 10.1001/ jamapediatrics.2017.1689.
134. Romeo DMM, Cioni M, Palermo F, et al. Neurological assessment in infants discharged from a neonatal intensive care unit. Eur J Paediatr Neurol 2013;17(2):192-198. DOI: 10.1016/j.ejpn.2012.09.006.

135. Kwong AK, Eeles AL, Olsen JE, et al. The baby moves smartphone app for general movements assessment: engagement amongst extremely preterm and term-born infants in a state-wide geographical study. J Paediatr Child Health 2019;55(5):548-554. DOI: 10.1111/jpc.14240. 